\title{
AN INVESTIGATION OF THE INFLUENCE OF DIAPHRAGM FLEXIBILITY ON BUILDING DESIGN THROUGH A COMPARISON OF FORCED VIBRATION TESTING AND COMPUTATIONAL ANALYSIS
}

\author{
A Thesis \\ presented to \\ the Faculty of California Polytechnic State University, \\ San Luis Obispo
}

In Partial Fulfillment of the Requirements for the Degree Master of Science in Architecture with a Specialization in Architectural Engineering

by

Blake Alan Roskelley

October 2010 
(C) 2010

Blake Alan Roskelley

ALL RIGHTS RESERVED 


\section{COMMITTEE MEMBERSHIP}

TITLE:

AUTHOR:

DATE SUBMITTED:

COMMITTEE CHAIR:

COMMITTEE MEMBER:

COMMITTEE MEMBER:
An Investigation of the Influence of Diaphragm Flexibility on Building Design through a Comparison of Forced Vibration Testing and Computational Analysis

Mr. Blake Alan Roskelley

October 2010

Dr. Graham Archer, P.Eng.

Mr. Kevin Dong, SE 


\begin{abstract}
An Investigation of the Influence of Diaphragm Flexibility on Building Design through a Comparison of Forced Vibration Testing and Computational Analysis Blake Alan Roskelley

An assessment of the validity of idealizing a concrete diaphragm as rigid was performed through the modal analysis of three existing buildings. Modal analysis was performed both by physical experimentation and computational analysis. Experimental determination of the mode shapes shows that two of the three buildings' diaphragms exhibited flexible behavior. The experimental results were compared to computational analysis results and were shown to be similar, confirming that that the two building diaphragms are not rigid. As a standard, diaphragms with aspect ratios less than three are permitted to be idealized as rigid per ASCE 7-05. To determine the effect of the rigid diaphragm idealization, the design forces and roof deflections for each building were determined from the computational model through a spectral analysis for both a model with rigid diaphragms and a model with semi-rigid diaphragms. It was found that the design seismic demands for the two buildings with flexible diaphragms were higher when modeled with semi-rigid diaphragms than with rigid diaphragms. The conclusion is made that idealizing a concrete diaphragm as rigid solely based on its aspect ratio may result in an unconservative estimate of the seismic demands on a building.
\end{abstract}

Keywords: Modal Analysis, Forced Vibration, Rigid Diaphragm Assumption 


\section{Contents}

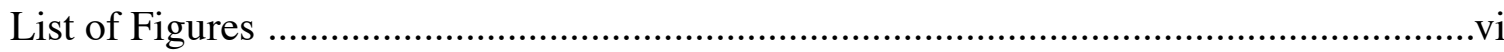

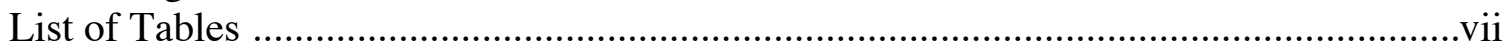

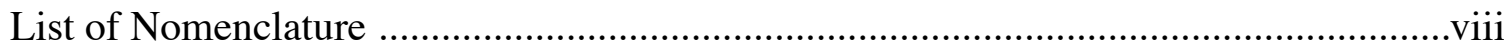

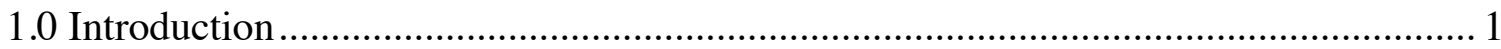

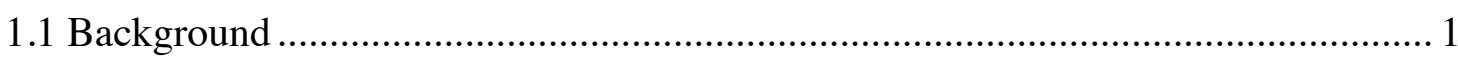

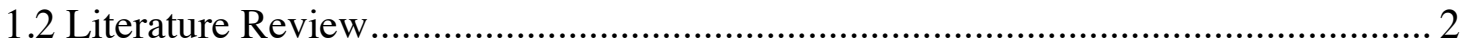

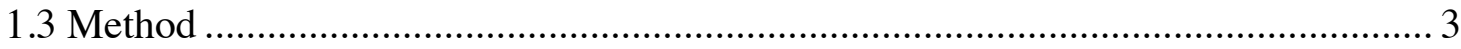

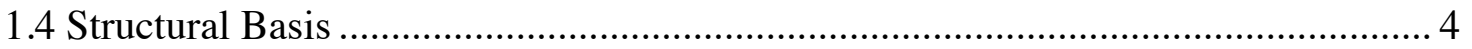

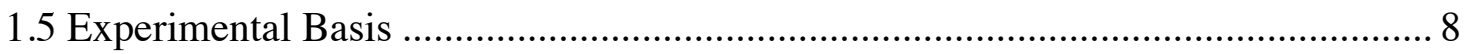

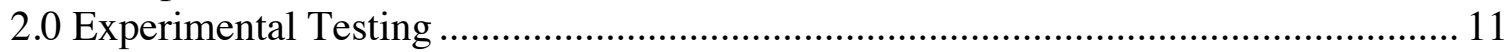

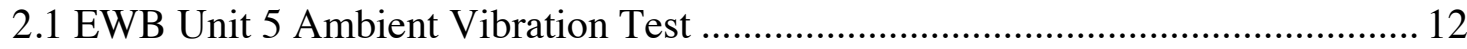

2.2 EWB Unit 5 Forced Vibration Test ................................................................. 14

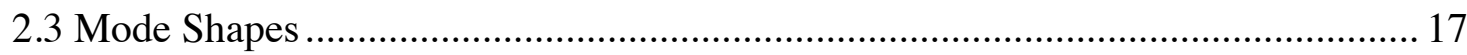

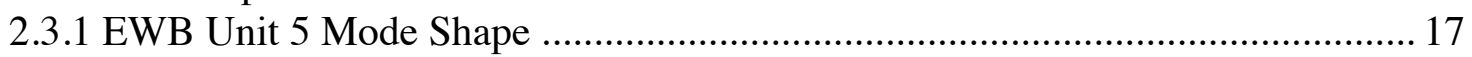

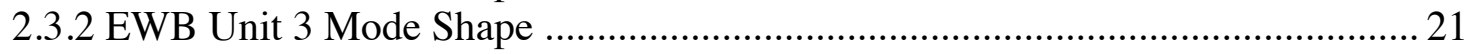

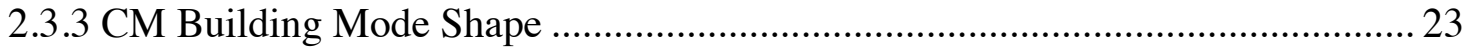

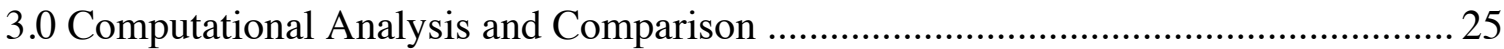

3.1 EWB Unit 5 Computational Model ................................................................... 26

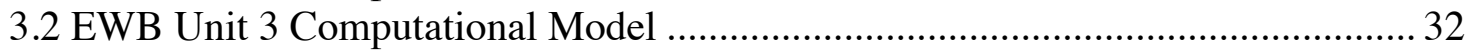

3.3 CM Building Computational Model ............................................................... 34

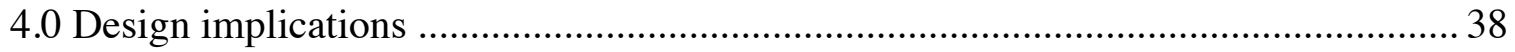

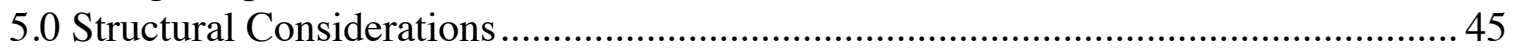

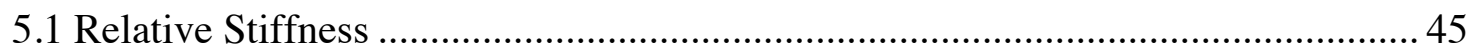

5.2 Additional Sources of Building Stiffness .......................................................... 48

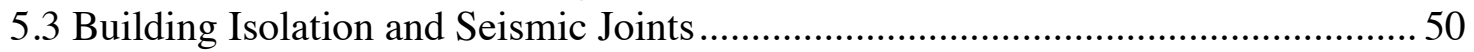

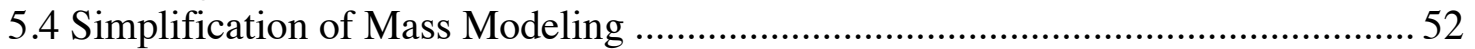

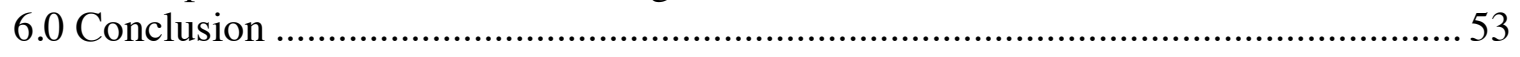

7.0 Reference 


\section{List of Figures}

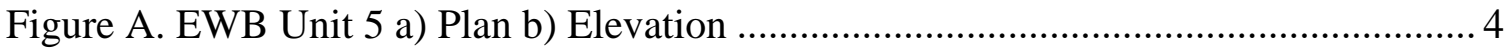

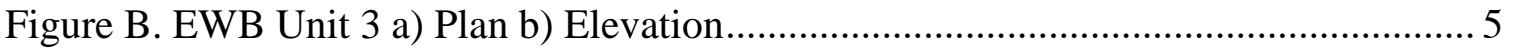

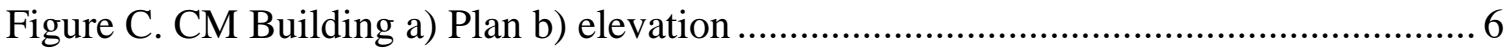

Figure D. EWB Unit 5, EWB Unit 3, CM Building Plan View ........................................ 7

Figure E. Test Equipment (Shaker, Computer, Accelerometer) .......................................... 8

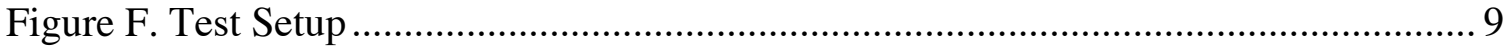

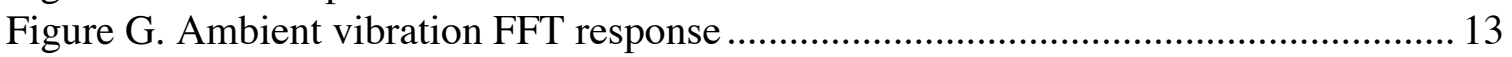

Figure H. EWB Unit 5 Floor Forced vibration response ............................................... 14

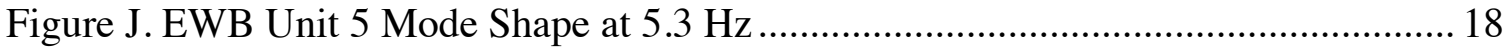

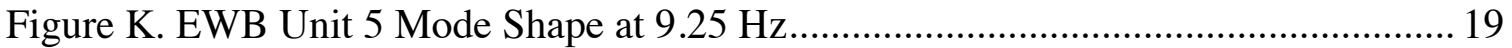

Figure L. EWB Unit 5 Elevation View of Mode Shape at 5.3 and $9.25 \mathrm{~Hz}$................... 20

Figure M. EWB Unit 3 Floor EW Mode Shape at $6.4 \mathrm{~Hz}$........................................... 22

Figure N. CM Building 3rd Floor NS Mode Shape at $3.61 \mathrm{~Hz}$.................................... 23

Figure P. EWB Unit 5 Computer Generated Model ..................................................... 26

Figure Q. EWB Unit 5 Computational Floor $1^{\text {st }}$ Mode Shape \& Experimental ............... 28

Figure R. EWB Unit 5 Computational Floor $2^{\text {nd }}$ Mode Shape \& Experimental ............... 29

Figure S. EWB Unit 5 Computational Vertical Mode Shape 1 and 2 .............................. 31

Figure T. EWB Unit 3 Computer Generated Model ......................................................... 32

Figure U. EWB Unit 3 Floor First EW Mode Shape ........................................................ 33

Figure V. CM Building Computer Generated Model ………………………………........ 35

Figure W. CM Building $3^{\text {rd }}$ Floor First NS Mode Shape ................................................. 36

Figure X. ASCE 7-05 Design Response Spectrum...................................................... 38

Figure Y. SAC Averaged Response Spectra with Trend Line.......................................... 40

Figure Z. Plot of Deformation Ratio to Relative Stiffness Ratio ....................................... 47 


\section{List of Tables}

Table 1. Diaphragm Aspect Ratios ............................................................................... 7

Table 2. Experimentally Determined Modal Frequencies ................................................ 16

Table 3. EWB Unit 5 Mode 1 Floor Diaphragm Rotations .............................................. 21

Table 4. EWB Unit 3 Floor Diaphragm Rotations ........................................................... 22

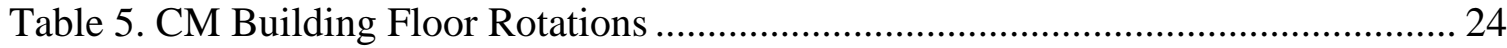

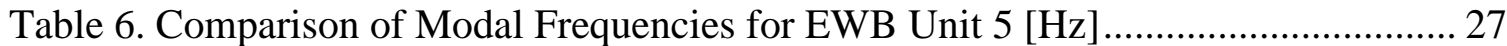

Table 7. Comparison of MAC Numbers for EWB Unit 5 ............................................ 30

Table 8. Comparison of Modal Frequencies EWB Unit $3[\mathrm{~Hz}]$...................................... 32

Table 9. Comparison of MAC Numbers for EWB Unit 3 .............................................. 34

Table 10. Comparison of CM Building Modal Frequencies [Hz] ................................... 35

Table 11. Comparison of MAC Numbers for CM Building ............................................ 37

Table 12. ASCE7-05 Comparison of Design Parameters ................................................. 41

Table 13. SAC Comparison of Design Parameters ........................................................ 43

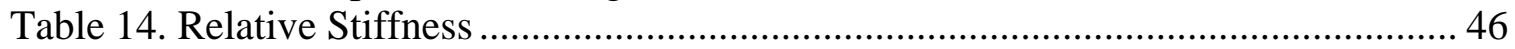




\section{List of Nomenclature}

ASCE - American Society of Civil Engineers

$\mathrm{CM}$ - Construction Management

COMP - computer or computational

DBE - Design Basis Earthquake

EW - east-west

EWB - Engineering West Building

EXP - experimental or experiment

FFT - Fast Fourier Transform

$\mathrm{g}$ - Units of Gravity

$\mathrm{Hz}-$ Hertz

ksi - kips per square inch

LFRS - Lateral Force Resisting System

MAC - Modal Assurance Criterion

MCE - Maximum Considered Earthquake

MEP - Mechanical, Electrical, and Plumbing

NS - north-south

psf - pounds per square foot

rms - Root Mean Square

$\mu \mathrm{g}$ - Units of Gravity Times Ten to the Minus 6 
Introduction 1

1.0 INTRODUCTION

Retrofit schemes and new building designs are often based on computer models created in structural analysis software programs. These programs allow the designer to approximate the results for a building's modal periods of vibration and mode shapes. Computer programs are often used by a designer to determine the forces used in the design of the lateral force resisting system. A designer makes many assumptions that affect the results of the computational output. One decision that can have considerable effect on building analysis and design is the rigidity of the diaphragm. The floor and roof diaphragms can be defined as rigid or semi-rigid, and it is up to the designer to determine which designation is more accurate.

ASCE 7-05 allows a building designer to idealize a concrete diaphragm as rigid solely based on the diaphragm's aspect ratio. It states

12.3.1.2 Rigid Diaphragm Condition. Diaphragms of concrete slabs or concrete filled metal deck with span to dept ratios of 3 or less in structures that have no horizontal irregularities are permitted to be idealized as rigid.

This thesis investigates the effect that idealizing a diaphragm as rigid has on building design and addresses the validity of the above statement (ASCE 7-05 2006).

\subsection{Background}

This thesis will evaluate the rigidity of the concrete floor diaphragms of three buildings by performing a modal analysis both through physical experimentation and computational analyses. Modal analysis of structures is concerned with determining the structure's modal parameters. The modal parameters of a structure can be determined both experimentally and by computational analyses. Through experimental testing the

\footnotetext{
An Investigation of the Influence of Diaphragm Flexibility on Building Design through a Comparison of Forced Vibration Testing and Computational Analysis
} 
Introduction 2

structure can be analyzed by the means of ambient or forced vibration to determine its modal parameters. The structure can also be modeled (based on its configuration, taking into consideration mass, stiffness, and damping properties) and analyzed through the use of a computation model.

\subsection{Literature Review}

A method for using ambient vibration measurements to determine natural frequencies, damping ratios, and mode shapes was presented by Kondo and Hamamoto in their article "Local damage detection of flexible offshore platforms using ambient vibration measurement". The authors compared the change in the curvature of mode shapes between damaged and undamaged states. They then quantitatively evaluated the damage in a particular location of the structure by a perturbation method detailed in their article (Kondo and Hamamoto 1994). This paper's use of modal analysis by ambient vibration testing served as a basis for the testing of the structures in the current project. Others have done research using ambient vibration to perform modal analyses as well (Trifunac 1972) (Ivanovic and Todorovska 2000) (Feng and Xue 1998).

Forced vibration testing was done on an existing four-story reinforced concrete building damaged by the 1994 Northridge earthquake to predict the future response of the structure. In "Forced Vibration Testing of a Four Story Reinforced Concrete Building Utilizing the NEES@UCLA Mobile Field Laboratory" the authors reported the results received from a large array of accelerometer sensors throughout the structure. Building accelerations were excited by ambient vibrations and forced vibrations, using two eccentric mass shakers with force capability of 100 kips each and a linear shaker with a 
Introduction 3

force capability of 15 kips. In their conclusion, the authors suggested further assessment of their results to determine the degree of damage that resulted from the Northridge earthquake. They suggested analyzing local site specific ground motions and performing nonlinear structural analysis (Yu and Wallace 2008). Similar research has been done on a 15 story steel moment-resisting frame building (Skolnik and Wallace 2006). A similar approach to forced vibration and response data acquisition was used for the testing in this thesis (Yu 2005).

The experimental results for the modal frequencies from the testing performed by McDaniel and Archer in their papers "Improving Student Understanding of Structural Dynamics Using Full-Scale, Real-time Excitation of Buildings" and "Full-Scale RealTime Building Dynamics Laboratory" were used in this thesis (McDaniel and Archer 2010b; 2010a). Also, the same method for determining the experimental results for the modal frequencies and mode shapes detailed in those papers was used in this thesis.

\subsection{Method}

This thesis documents the procedure, records the data, and compares the results of the experimental testing of three buildings to computational models. The modal parameters obtained from both analyses are compared for each building. The modal parameters include the modal frequencies of vibration, the mode shapes, and the modal damping. For the purposes of this thesis the modal frequencies and mode shapes are primarily investigated because they are the parameters that are most affected by the rigidity of the floor diaphragms. After determining the affect that the diaphragm rigidity has on the building design, the thesis then investigates what building characteristic has 
Introduction 4

the most effect on the rigidity of the diaphragm. Careful consideration is given to building aspect ratio, relative stiffness of diaphragm to the adjoining vertical elements of the lateral force resisting system, additional nonstructural stiffness, and the interaction of buildings at seismic joints.

\subsection{Structural Basis}

The structures investigated in this thesis are located on the campus of California Polytechnic State University, San Luis Obispo. The first building is Unit 5 of the Engineering West Building 21 (EWB Unit 5). See Figure A below.
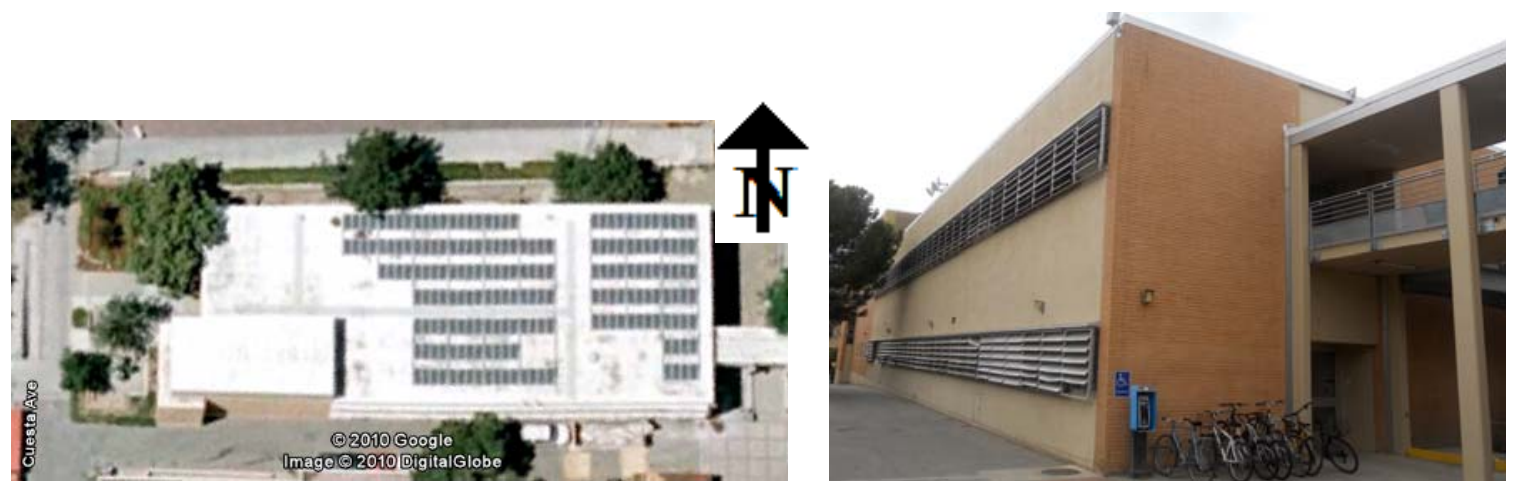

Figure A. EWB Unit 5 a) Plan b) Elevation

Source: a) Google Maps b) Author

EWB Unit 5 is a wing separate from the rest of the Engineering West building.

The structure is two stories tall and rectangular with dimensions $60^{\prime}$ in the north-south direction and $160^{\prime}$ in the east-west direction. It is composed of steel columns and beams encased in concrete. The floor and roof diaphragms are $4 \frac{1}{2} "$ thick concrete slabs. In the north-south direction there are brick shear walls running the entire length of the east and west exterior walls. The exterior east-west shear walls are two withes thick with grout between each withe and nominal reinforcement. The shear walls run from the foundation to the roof. In the east-west direction there is an 8 " thick concrete shear wall $20^{\prime}$ north of 
Introduction 5

the south exterior wall that runs the entire length of the building. It is two stories in height and perforated at the ground floor and the second floor by four $8^{\prime}$ by $3^{\prime}$ doors at approximately $30^{\prime}$ on center.

In addition to EWB Unit 5, two other structures also located on the Cal Poly campus were investigated. The first tested was Unit 3 of Engineering West Building 21 (EWB Unit 3). This building is of similar construction to EWB Unit 5. It is a two story building with a partial basement on the south end of the building. It is rectangular with dimensions $138^{\prime}$ in the north-south direction and $48^{\prime}$ in the east-west direction. Similar to EWB Unit 5, EWB Unit 3 has steel wide flange beams and columns encased in concrete. Unlike EWB Unit 5 it does not have masonry shear walls but only smaller $20^{\prime}$ long concrete shear walls in various locations, as seen in Figure D on page 7. Also, it does not have one large full length concrete shear wall like EWB Unit 5. This building was chosen in order to compare and verify the results of EWB Unit 5 because of its similarity in construction type and diaphragm aspect ratio. See Figure B below.

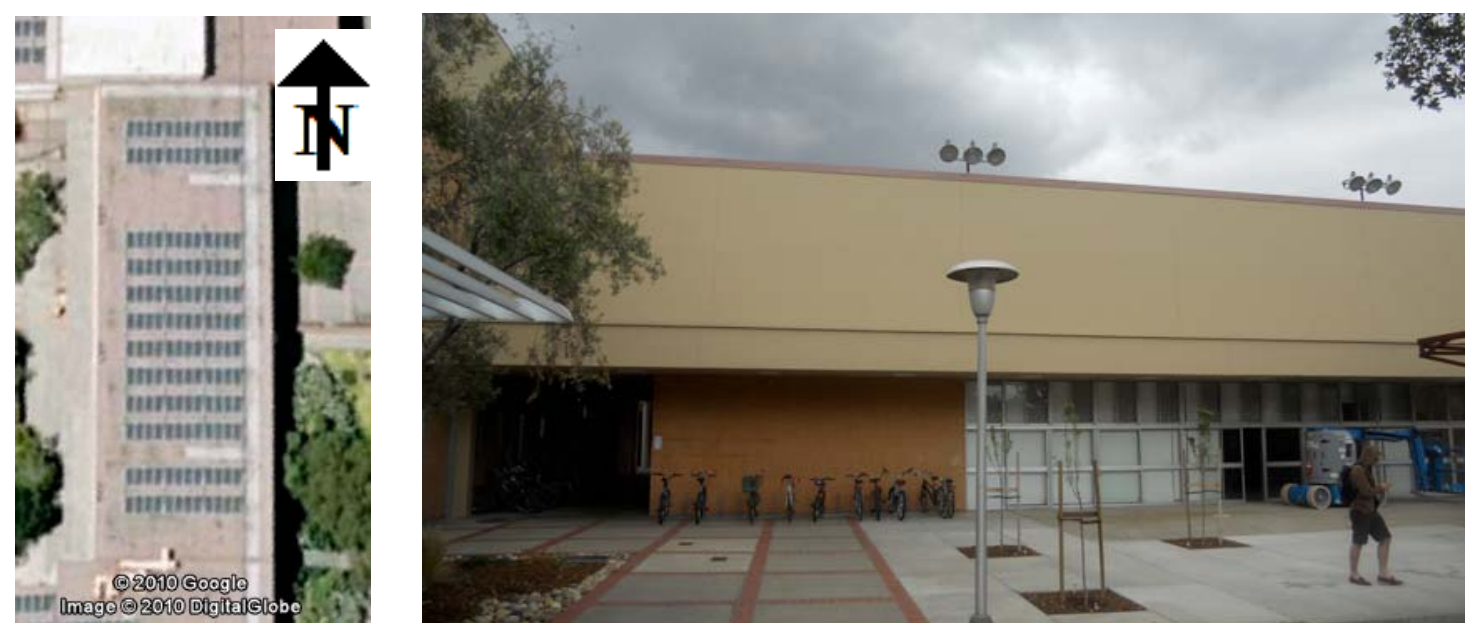

Figure B. EWB Unit 3 a) Plan b) elevation Source: a) Google Maps b) author

An Investigation of the Influence of Diaphragm Flexibility on Building Design through a Comparison of Forced Vibration Testing and Computational Analysis 
Introduction 6

The third building tested was the Construction Management Building 186 (CM

Building). This building is a steel braced frame structure. The building is three stories

tall. It is ' $\mathrm{L}$ ' shaped and 198 ' in the east-west direction and 60' in the north-south

direction with a $40^{\prime}$ by $30^{\prime}$ appendage on the south east end of the building. It has $3 "$

concrete over 3" metal deck floor diaphragms and there is no concrete fill over the 3"

metal deck roof diaphragm. See Figure C below.
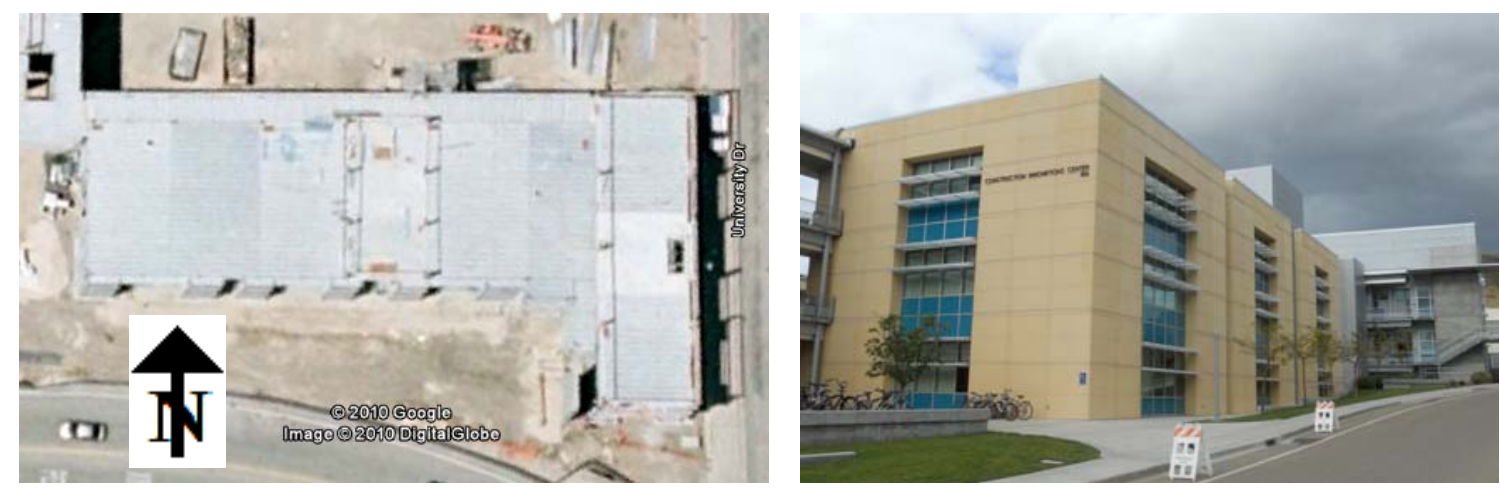

Figure C. CM Building a) Plan b) elevation

Source: a) Google Maps b) author

Figure D, on the next page, shows a plan view of each building with the

dimensions of the floor diaphragms and the locations of the lateral force resisting

elements.

An Investigation of the Influence of Diaphragm Flexibility on Building Design through a Comparison of Forced Vibration Testing and Computational Analysis 
Introduction 7

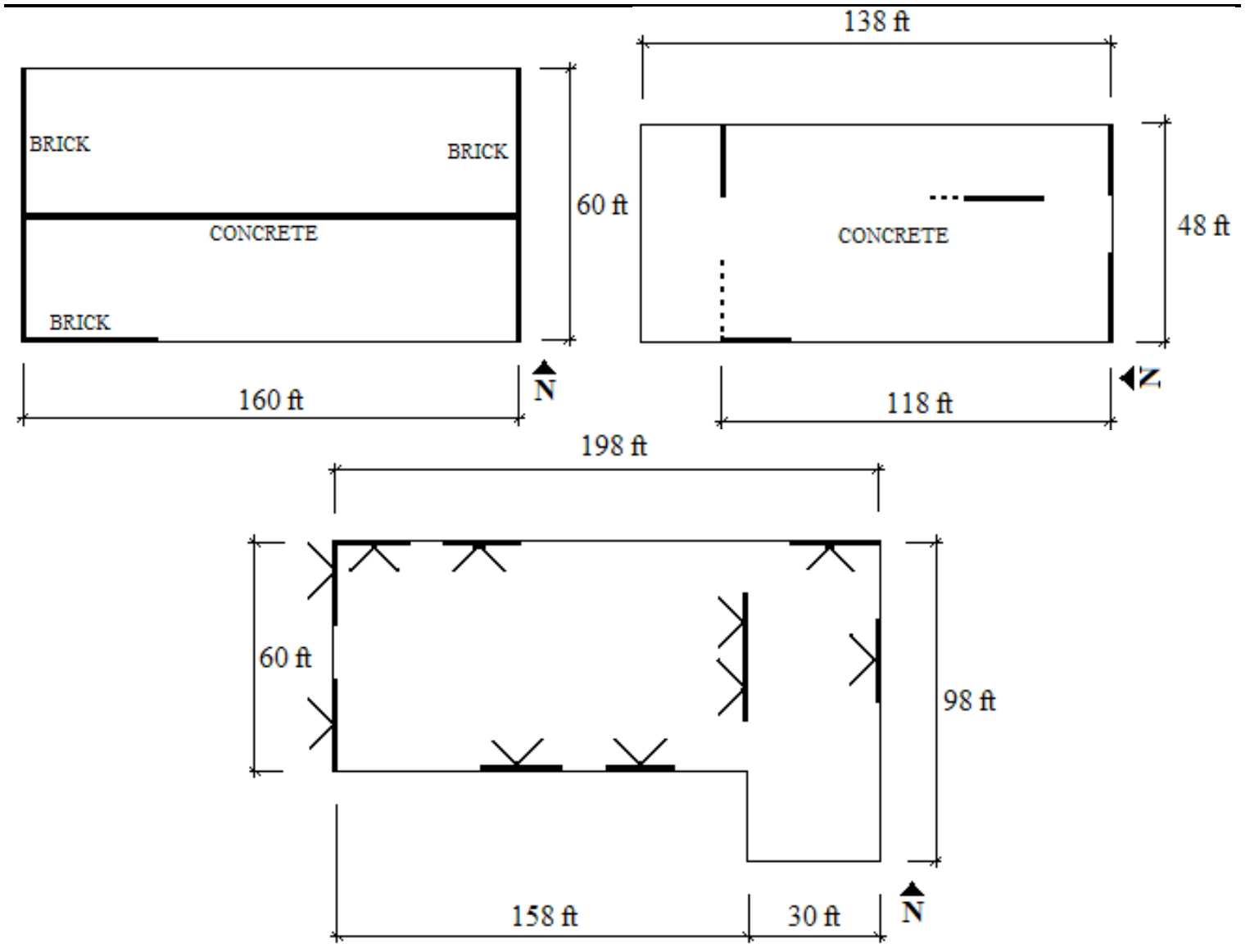

Figure D: EWB Unit 5, EWB Unit 3, CM Building Plan View

The aspect ratio of each building is listed in Table 1 below.

Table 1. Diaphragm Aspect Ratios

\begin{tabular}{|c|c|c|}
\cline { 2 - 3 } \multicolumn{1}{c|}{} & \multicolumn{2}{c|}{ Aspect Ratio } \\
\cline { 2 - 3 } \multicolumn{1}{c|}{} & Weak & Strong \\
\hline EWB Unit 5 & $2.67: 1$ & $.375: 1$ \\
\hline EWB Unit 3 & $2.46: 1$ & $.407: 1$ \\
\hline CM Bldg & 2.63 & $.400: 1$ \\
\hline
\end{tabular}

All the buildings investigated in this thesis have aspect ratios of less than three.

Therefore, according to ASCE 7-05 their diaphragms may be idealized as rigid. The following testing was done to verify the validity of this idealization. If it is correct to

An Investigation of the Influence of Diaphragm Flexibility on Building Design through a Comparison of Forced Vibration Testing and Computational Analysis 
Introduction 8

make this idealization, then the buildings should show rigid diaphragm behavior. And, if they do not show rigid diaphragm behavior then the design of the buildings should not be adversly affected by idealizing the diaphragms as rigid in order for the code provision to be valid.

\subsection{Experimental Basis}

Testing equipment was set up on all three sites for the purpose of achieving experimental results for the resonance frequencies and mode shapes. The testing equipment consists of the following:

- Accelerometers

- Data Acquisition (DAQ)

- Dell Computer with LabView Software

- Electronic Signal Generator

- Amplifier

- Linear Mass Shaker

The test setup is depicted in Figure E below and Figure F on the next page.

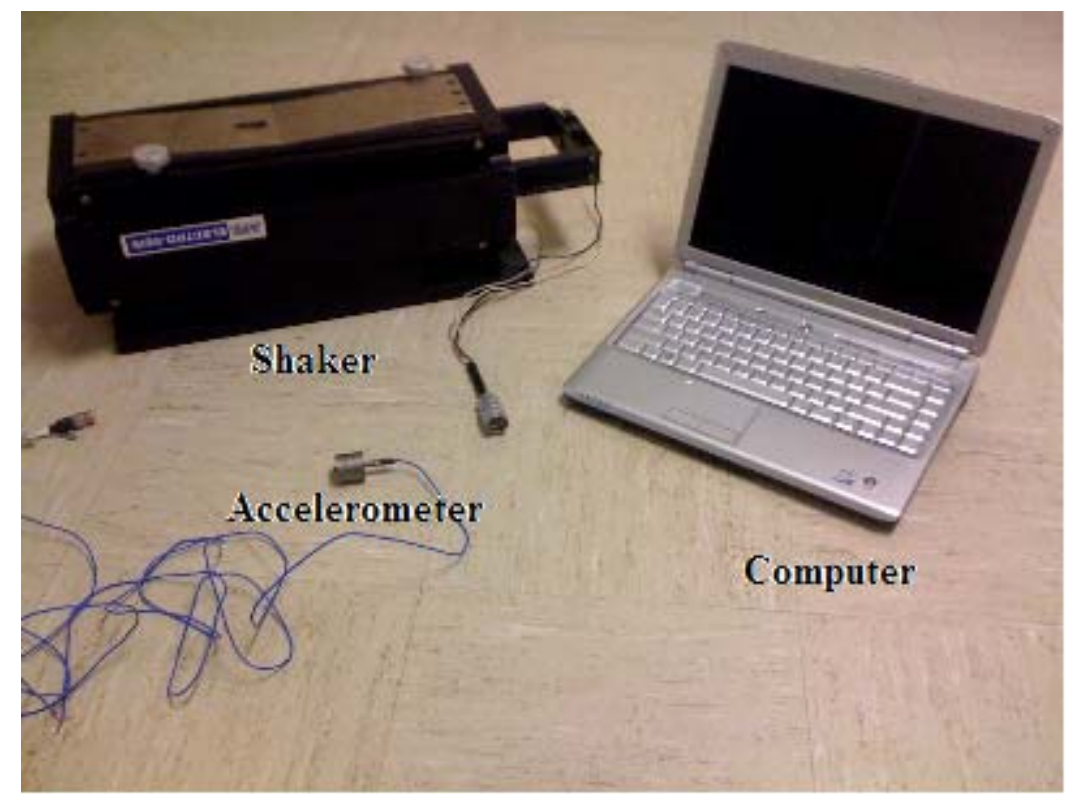

Figure E: Test Equipment (Shaker, Computer, Accelerometer) Source: Author

An Investigation of the Influence of Diaphragm Flexibility on Building Design through a Comparison of Forced Vibration Testing and Computational Analysis 
Introduction 9

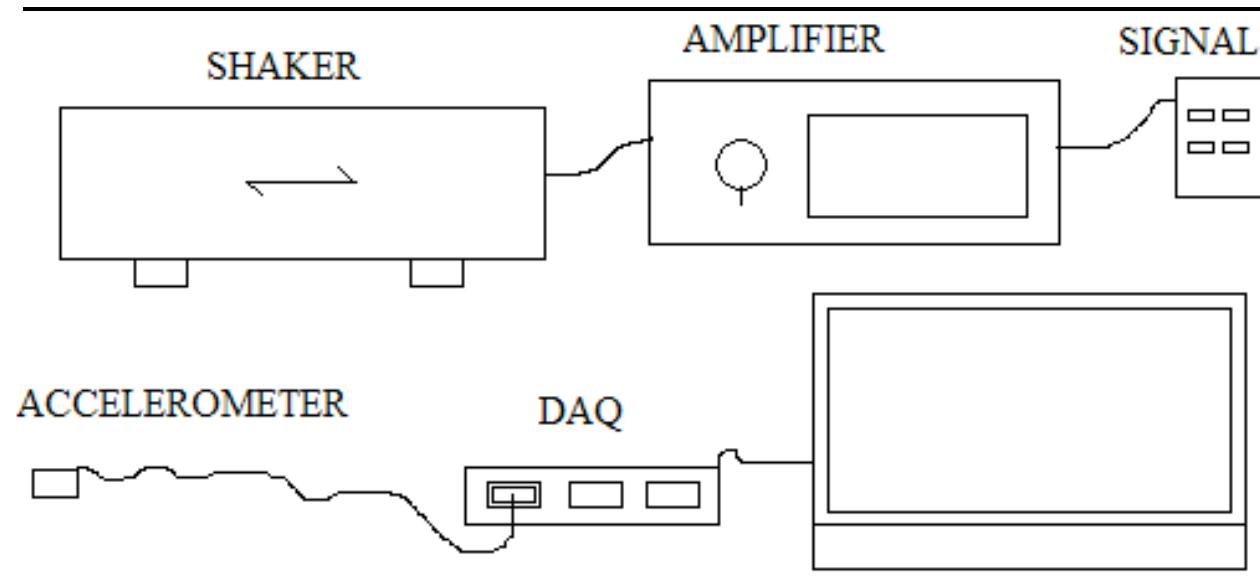

COMPUTER

\section{Figure F: Test Setup}

Source: Author

The building motion is captured by three accelerometers strategically placed on

the building diaphragm. Generally, there are two accelerometers set up to measure translational motion and another accelerometer oriented parallel to one of the translation measuring accelerometers to capture rotation of the diaphragm about a vertical axis. The rotation is calculated from the equation

$$
\frac{A_{1}-A_{2}}{x} * g,
$$

where $A_{1}$ and $A_{2}$ represent accelerations of two parallel accelerometers (g), $g$ is acceleration due to gravity $\left(\mathrm{ft} / \mathrm{sec}^{2}\right)$, and $x$ is the distance between the accelerometers $A_{1}$ and $A_{2}(\mathrm{ft})$.

This equation results in a value for rotation with the units of $\mathrm{rad} / \mathrm{sec}^{2}$. The accelerometers have a frequency range of less than $1 \mathrm{~Hz}$ to greater than $200 \mathrm{~Hz}$ and have advertised broadband resolutions of 1-3 $\mu \mathrm{g}$ rms. A DAQ digital converter transforms the analog signal from the accelerometers into a digital signal for processing by a computer with LabView software. The software displays a time history view of the acceleration amplitude recorded alongside a Fast-Fourier Transform (FFT) plot of the absolute An Investigation of the Influence of Diaphragm Flexibility on Building Design through a Comparison of Forced Vibration Testing and Computational Analysis 
Introduction 10

$\overline{\text { response of each frequency obtained. The FFT view is necessary to determine the relative }}$ signs (positive or negative) of the different accelerometer responses.

The forced vibration is produced by a 100 pound portable long-stroke linear mass shaker with the capability of generating a constant sinusoidal force of 30 pounds. The shaker's frequency range is approximately 2-20 Hz. Mechanical attachment of the shaker to the structural diaphragm is not necessary. Friction at the shaker base is sufficient to transfer the motion of the shaker into the structure due to the small forces that are generated (McDaniel and Archer, 2010a). 
Experimental Testing 11

\subsection{EXPERIMENTAL TESTING}

The test equipment, described in Section 1.5 and starting on page 8, was used to perform a forced vibration test of EWB Unit 5, EWB Unit 3, and the CM Building. The purpose of forced vibration testing is to obtain the natural frequencies of vibration, the mode shapes and damping of a building.

To validate and verify the ability of a 30 pound linear mass shaker to produce measurable accelerations in a nearly 2,000 ton building, a hand calculation was performed to determine the level of accelerations that 30 pounds of force would produce on such a building analytically. As a basis for this calculation the EWB Unit 5 was used. The mass matrix was assembled through an estimation of the building weight. The damping used was determined to be $1.67 \%$ from the experimental results of the forced vibration test at the first mode. The mode shape for three degrees of freedom (two translational degrees of freedom and one rotational degree of freedom) at the center of mass of the floor and roof, and the modal frequencies of vibration were determined through computational analysis in computer software. The mode shape was mass orthonormalized. The acceleration, at the first degree of freedom, (at the floor in the north/south direction) produced when the building is forced at the floor, at the first modal frequency, by a 30 pound sine wave was then calculated (Chopra 2007). The equations used are

$$
\begin{gathered}
q=C * \sin (t)+D * \cos (t), \\
U=\Phi_{\text {norm }} * q, \\
A=U * \omega^{2},
\end{gathered}
$$

where $q$ represents the modal coordinates, $C$ and $D$ represent coefficients defined by Chopra on page 480 of his text, 
Experimental Testing 12

$t$ represents time from 0 to $2 *$ pi,

$\Phi_{\text {norm }}$ represents the orthonormalized mode shape vector,

$U$ represents the nodal displacements vector,

$\omega$ represents the modal frequencies vector, and

$A$ represents the nodal accelerations vector.

The calculation resulted in a value for acceleration at the floor in the north-south degree of freedom of $0.0842 \mathrm{in} / \mathrm{sec}^{2}$, which is equal to $2.18 \times 10^{-4} \mathrm{~g}$ or $218 \mu \mathrm{g}$. The average response measured experimentally by the accelerometers at the first floor, at the center of mass, at the first mode was $233 \mu \mathrm{g}$. The percent difference between these two values is $6.4 \%$.

\subsection{EWB Unit 5 Ambient Vibration Test}

Initially, an ambient vibration test was performed in order to obtain a baseline for EWB Unit 5. Two accelerometers were placed at the approximate center of mass of EWB Unit 5. The accelerometers were oriented perpendicular to each other, one in the eastwest direction and one in the north-south direction of the building. An additional accelerometer was placed 16' away from the accelerometer oriented in the north-south direction and was oriented in the same direction in order to determine rotational accelerations. A distance of $16^{\prime}$ was determined to produce a rotational magnitude in the same range as the translational response. The results of the FFT plot of the ambient vibration test are shown below in Figure $\mathrm{G}$ on the following page. The units of the translation response are in acceleration (g) and the units of the rotational response are in $\mathrm{rad} / \mathrm{s}^{2}$ as described previously.

\footnotetext{
An Investigation of the Influence of Diaphragm Flexibility on Building Design through a Comparison of Forced Vibration Testing and Computational Analysis
} 


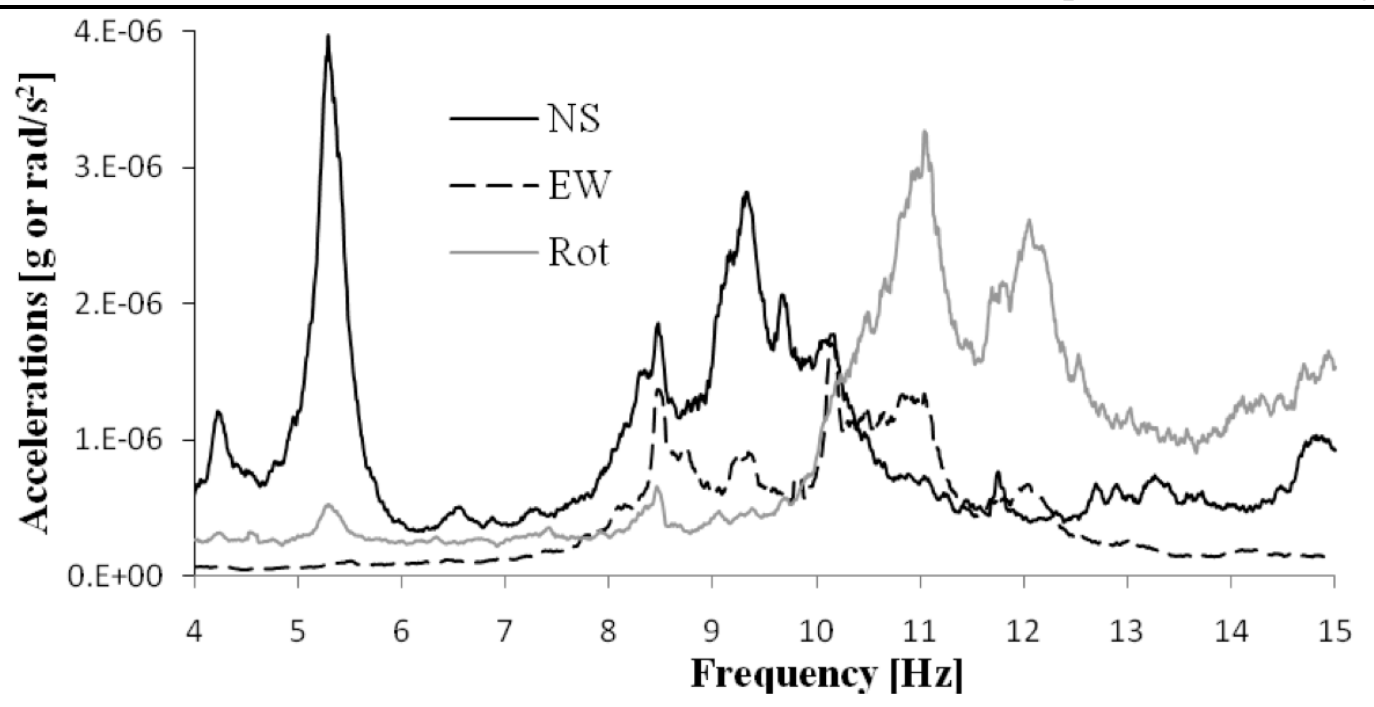

Figure G: Ambient vibration FFT response

Inititially, the plot showed three very large and distinct spikes that dwarfed the rest of the plot. A modal frequency will appear on the FFT plot as a curved peak. The sharpness of the peak depends on the amount of damping in that particular mode. A sharp peak suggests that the structure does not provide a significant amount of damping at that frequency. Because of the sharpness of several of the peaks in the ambient vibration response FFT plot, it was determined that they were due to mechanical units or other oscillating devices on the roof or other parts of the building. Therefore, these extremely sharp peaks were truncated (thus not visible in the plot in Figure G on the previous page) and disregarded as potential modal frequencies of vibration.

There appears to be a natural frequency just above $5 \mathrm{~Hz}$ and $9 \mathrm{~Hz}$ in the northsouth direction. The east-west response is much smaller and less clear than the northsouth. There also appears to be a rotational natural frequency at $11 \mathrm{~Hz}$ to $12 \mathrm{~Hz}$.

\footnotetext{
An Investigation of the Influence of Diaphragm Flexibility on Building Design through a Comparison of Forced Vibration Testing and Computational Analysis
} 
Experimental Testing 14

\subsection{EWB Unit 5 Forced Vibration Test}

After the ambient test was performed, the linear mass shaker was set up at the building's approximate center of mass on the floor diaphragm. The shaker was set to sweep between frequencies from $4 \mathrm{~Hz}$ to $10 \mathrm{~Hz}$ on an interval of 120 seconds. In LabView, the data was recorded ten times (making a total test period of 20 minutes) and then averaged to create one plot. The same process was repeated for frequencies between $10 \mathrm{~Hz}$ and $15 \mathrm{~Hz}$. The shaker was set up to sweep in both translational directions, northsouth and east-west. It was also placed away from the center of mass on a 45 degree angle in order to excite the building's rotational modes of vibration. The data was recorded and plotted on a scale of $4 \mathrm{~Hz}$ to $15 \mathrm{~Hz}$ as seen in Figure $\mathrm{H}$ below.

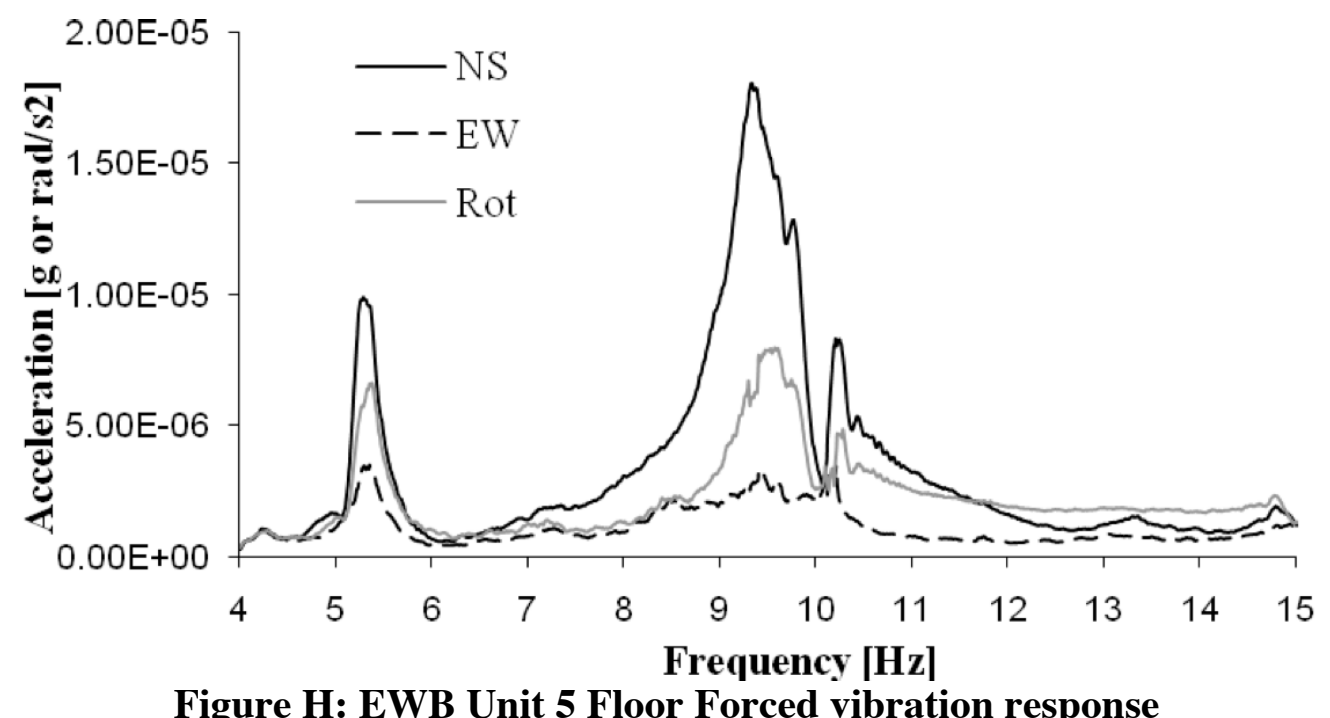

The forced vibration test showed that there were two (primarily north-south)

modes present. The modes occur at approximately $5.5 \mathrm{~Hz}$ and $9.5 \mathrm{~Hz}$. The break in sweeps is noticeable at just before $10 \mathrm{~Hz}$ in the plot as the response decreases dramatically and then increases again just after $10 \mathrm{~Hz}$. This break is due to the shaker's transition from high frequency output to low frequency output. Had the shaker been

An Investigation of the Influence of Diaphragm Flexibility on Building Design through a Comparison of Forced Vibration Testing and Computational Analysis 
Experimental Testing 15

allowed to sweep continuously through $10 \mathrm{~Hz}$, this break would not be present. The sweeps were set at small intervals because with shorter frequency intervals the shaker spent more time at each frequency. The added time at each frequency within the interval increased the magnitude of the response at the modal frequencies and made them clearer.

Two natural modes of vibration are clearly present from the forced vibration test, both of which are in the north-south direction (approximately $5.5 \mathrm{~Hz}$ and $9.5 \mathrm{~Hz}$ ). However, there are no other modes that clearly appear before $15 \mathrm{~Hz}$. The range of the equipment goes to approximately $25 \mathrm{~Hz}$; therefore, in order to ensure that no other modes were overlooked, a forced vibration test was also performed at these higher frequencies. However, no natural frequencies were found.

No modes were found in the east-west direction possibly because of the high stiffness of the lateral force resisting system in the east-west direction. There is an $8 "$ thick concrete shear wall that runs the full $160^{\prime}$ length and $28^{\prime}$ height of the building from east to west. Performing a rudimentary hand calculation for the in-plane natural mode of vibration for the shear wall alone produces a natural frequency of approximately $19 \mathrm{~Hz}$. The stiffness of the brick wall on the south side of the building and any other stiffness from columns or incidental stiffness was not included in the calculation. Therefore, the overall building natural frequency is likely even higher. The accuracy of the equipment comes into question between $20 \mathrm{~Hz}$ and $25 \mathrm{~Hz}$ because of the shaker's inability to provide a pure sinusoidal frequency output. Therefore, it is reasonable to assume that the translational east-west modal frequency occurs out of the range of the equipment. 
Experimental Testing 16

To confirm that the modal frequencies determined in the sweeps were correct, the shaker was programmed to force at those frequencies, $5.5 \mathrm{~Hz}$ and $9.5 \mathrm{~Hz}$. Then, readings were taken for the frequencies $0.5 \mathrm{~Hz}$ below and above $5.5 \mathrm{~Hz}$ and $9.5 \mathrm{~Hz}$ at intervals of $0.05 \mathrm{~Hz}$. The modal frequencies determined in the sweeps were confirmed to be at $5.3 \mathrm{~Hz}$ and $9.25 \mathrm{~Hz}$ as modes in the north-south direction of EWB Unit 5.

The modal frequencies for EWB Unit 3 and the CM Building were previously determined by McDaniel and Archer (McDaniel and Archer, 2010a; McDaniel and Archer, 2010b). Table 2 below shows the modal frequencies of EWB Unit 5, EWB Unit 3, and the CM Building and their direction. It is important to note that EWB Unit 5 is oriented with the long dimension in the east-west direction, EWB Unit 3 is oriented with the long dimension in the north-south direction, and the CM Building is oriented with the long dimension in the east-west direction. Only the frequencies for EWB Unit 5 were determined by this thesis, the others were published by McDaniel and Archer.

\section{Table 2. Experimentally Determined Modal Frequencies}

\begin{tabular}{|c|c|c|c|}
\hline Building & Mode & Frequency [Hz] & Direction \\
\hline \multirow{2}{*}{ Unit 5} & 1 & 5.3 & NS \\
\cline { 2 - 4 } & 2 & 9.25 & NS \\
\hline \multirow{2}{*}{ Unit 3 } & 1 & 5.3 & NS \\
\cline { 2 - 4 } & 2 & 6.4 & EW \\
\hline \multirow{2}{*}{$\mathrm{CM}$} & 1 & 3.6 & NS \\
\cline { 2 - 4 } & 2 & 3.95 & EW \\
\hline
\end{tabular}

This thesis is most concerned with those frequencies that occur in the direction orthogonal to the building's long dimension. These frequencies occur in the direction of the building's weak axis. For the purposes of this thesis, the weak direction is defined as the direction orthogonal to the building's long dimension. Therefore, EWB Unit 5 mode

\footnotetext{
An Investigation of the Influence of Diaphragm Flexibility on Building Design through a Comparison of Forced Vibration Testing and Computational Analysis
} 
Experimental Testing 17

1 and 2, EWB Unit 3 mode 2, and CM Building Mode 1 are those modes under investigation.

\subsection{Mode Shapes}

Having determined the modal frequencies, the mode shapes for each building's weak axis frequency were then mapped. Mode shape mapping is the process by which the physical deformational response of a building's footprint is determined. The mode shape shows the direction and relative magnitude of the response at each point of a building's diaphragm at a modal frequency.

It was necessary to map the mode shapes for each building, EWB Unit 5, EWB Unit 3, and the CM Building. The same procedure for obtaining the mode shapes of EWB Unit 5 was applied to the other two buildings as well.

\subsubsection{EWB Unit 5 Mode Shape}

The accelerometers were placed at particular locations throughout the floor and roof diaphragms to obtain readings for the response at each location. The locations at which the accelerometers were placed initially were chosen in order to obtain a comprehensive understanding of the motion of the diaphragm. An accelerometer was placed at the approximate building center of mass and another near the east building edge to capture the response at the east edge of the diaphragm. Both accelerometers were oriented in the north-south direction. The accelerometer at the building edge read approximately 40 percent the response at the center of mass at the first modal frequency, $5.3 \mathrm{~Hz}$. To determine the motion of the diaphragm between these two points, the entire floor in the north-south direction was mapped by placing an accelerometer approximately every 15 ' across the diaphragm. The roof was excited by placing the shaker at the floor An Investigation of the Influence of Diaphragm Flexibility on Building Design through a Comparison of Forced Vibration Testing and Computational Analysis 
Experimental Testing 18

diaphragm's center of mass. Measurements were also taken at various locations along the length of the roof diaphragm to map the mode shape along the length of the roof diaphragm. Due to water puddles from rain, the roof diaphragm could not be measured at the exact same locations as the floor diaphragm. The resulting mode shapes for the floor and roof diaphragm at the first north-south mode are seen in Figure $\mathrm{J}$ below.

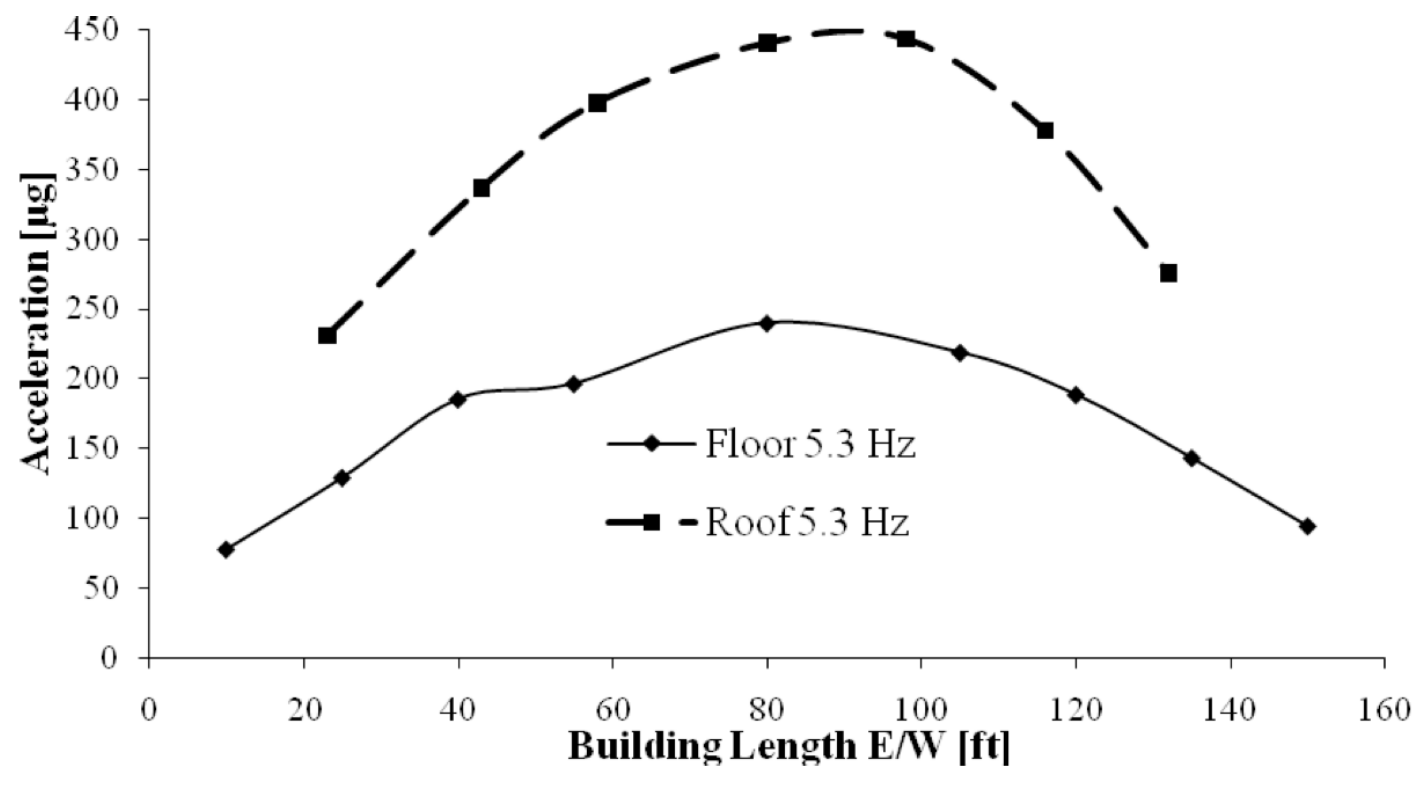

Figure J: EWB Unit 5 Mode Shape at $5.3 \mathrm{~Hz}$

The responses obtained at each location measured on the diaphragms are represented by the markers in the plot. The lines exist solely as a visual aid and do not suggest that the response between the points follows the line. The response at the roof was nearly twice that at the floor. This difference in magnitudes between the floor and roof can also be seen in the plot of the elevation view of the mode shape in Figure L on page 20. Extrapolating the two curves shows that at the edge of the building the response is approximately $20 \%$ that of the diaphragm center. The second mode shape, also in the 
Experimental Testing 19

north-south direction, was found in the same way as the first and can be seen in Figure $\mathrm{K}$ below.

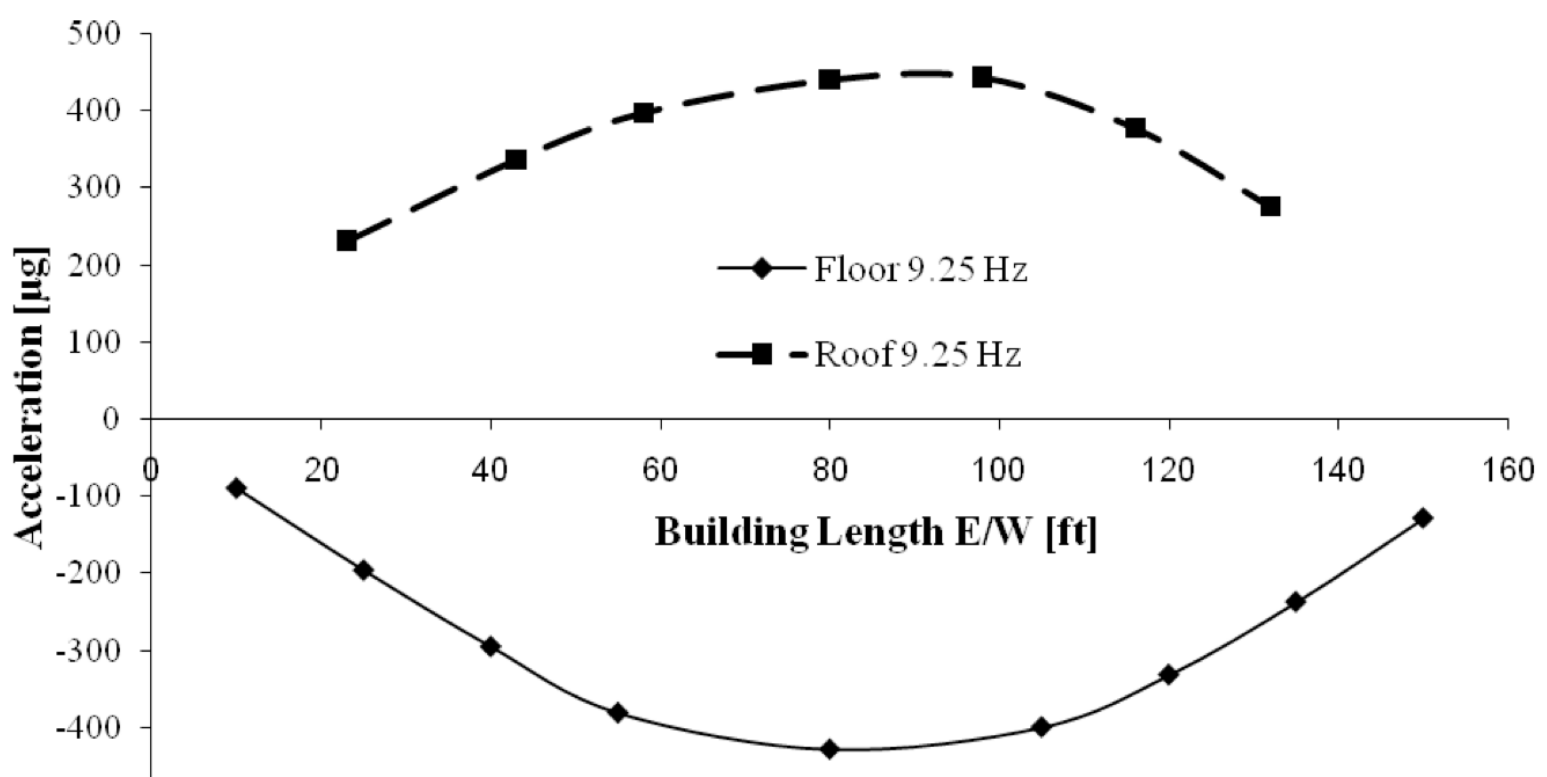

Figure K: EWB Unit 5 Mode Shape at $9.25 \mathrm{~Hz}$

The second mode occurs as the floor and roof deform out of phase with each other. Their responses have similar magnitudes but in opposite directions. Extrapolating the curves for the second mode at the roof and the floor would give a response at the edge of the building of approximately $10-20 \%$ that of the response at the center of mass. All four plots have a curved response distribution across the east-west length of the building diaphragm.

It was confirmed that the first mode was in fact the floor and the roof deforming in phase with each other and the second mode shape was the floor and roof deforming out of phase with each other in the same direction. Confirmation was made by placing an accelerometer at the floor and the roof simultaneously to capture the vertical building 
Experimental Testing 20

mode shape. Figure L below shows this elevation view of the mode shapes with measurements at the floor and the roof on the same plot.
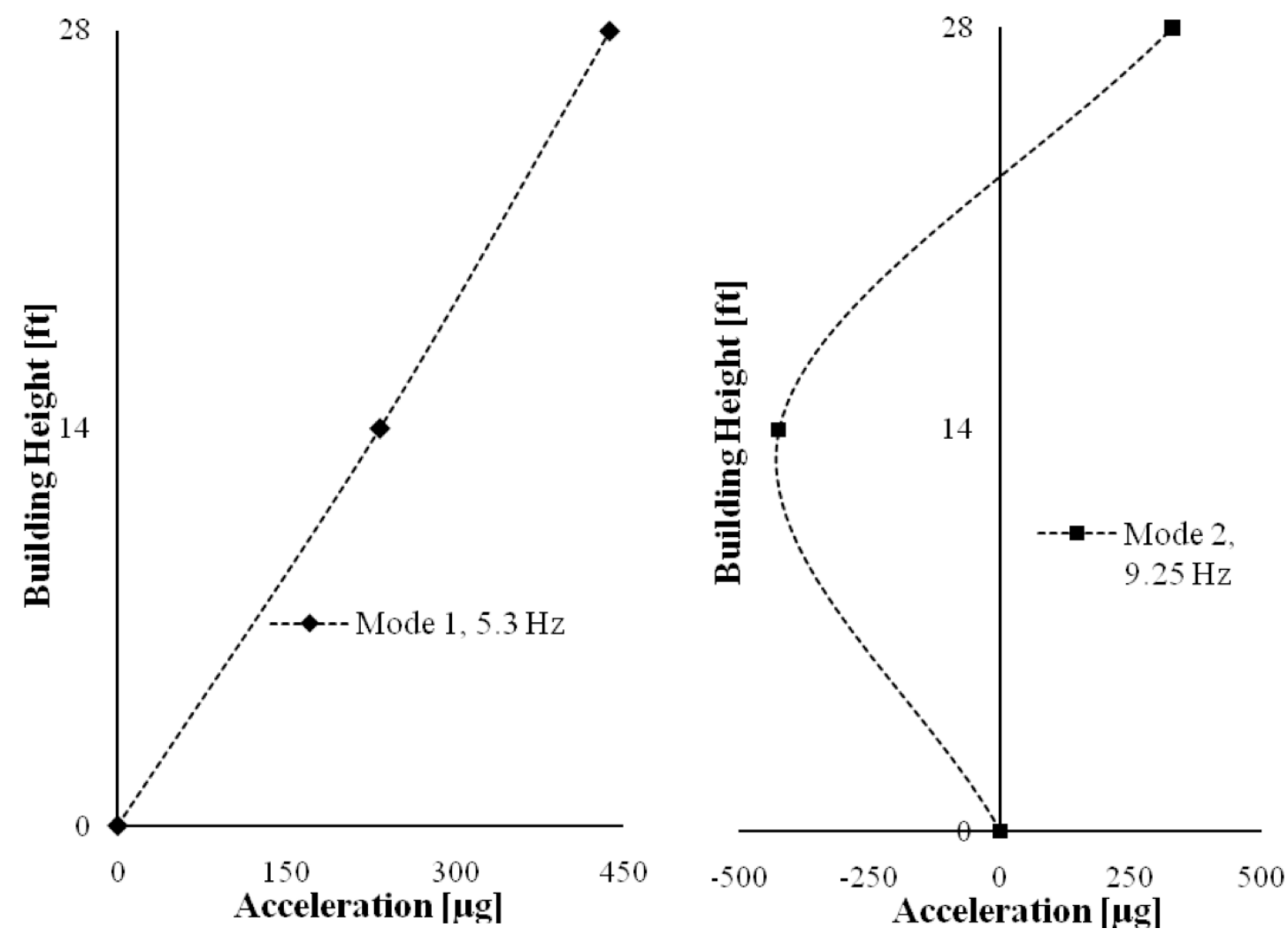

Figure L: EWB Unit 5 Elevation View of Mode Shape at 5.3 and $9.25 \mathrm{~Hz}$

The results from Figures $\mathrm{J}, \mathrm{K}$, and $\mathrm{L}$ suggest that the floor and roof diaphragms of EWB Unit 5 are not rigid. For a diaphragm to be considered rigid, the response of the diaphragm must be uniform across its length. Another way to determine if a diaphragm has rigid deformation is to investigate the rotational response along the length of the diaphragm. For a diaphragm to be considered rigid, the rotational response should be uniform throughout. Uniformity in rotational responses shows that the whole diaphragm is deforming at a similar magnitude and in the same direction. The rotations along the length of the floor diaphragm are found in Table 3 on the next page.

An Investigation of the Influence of Diaphragm Flexibility on Building Design through a Comparison of Forced Vibration Testing and Computational Analysis 
Table 3. EWB Unit 5 Mode 1 Floor Diaphragm Rotations

\begin{tabular}{|c|c|}
\hline Distance from Left End & Rotation $\left[\mathrm{rad} / \mathrm{s}^{2}\right]$ \\
\hline $20^{\prime}$ & 135 \\
\hline $50^{\prime}$ & 98.9 \\
\hline $80^{\prime}$ & 88.7 \\
\hline $100^{\prime}$ & 96.7 \\
\hline $130^{\prime}$ & 146 \\
\hline
\end{tabular}

It can be seen that the rotational response across the length of the diaphragm is not uniform. The greatest rotation occurs at the edges of the diaphragm. This progression makes sense because the slope of the translational response plot is the greatest at the building edge. Consideration should be given to the fact that the rotations are being determined by placing two accelerometers in the direction that the building is being forced. Therefore, the translational deformation of the diaphragm is included in the determination of the rotations and they cannot be compared directly because they are of different units. The rotational readings of the second mode and roof are similar, again suggesting that the floor and roof diaphragms of Engineering West Building Unit 5 are not rigid.

\subsubsection{EWB Unit 3 Mode Shape}

The same procedure described in the previous section was performed for EWB Unit 3. The floor mode shape was mapped to determine if it would exhibit rigid or semirigid deformation. The results are displayed in Figure $M$ on the next page.

\footnotetext{
An Investigation of the Influence of Diaphragm Flexibility on Building Design through a Comparison of Forced Vibration Testing and Computational Analysis
} 


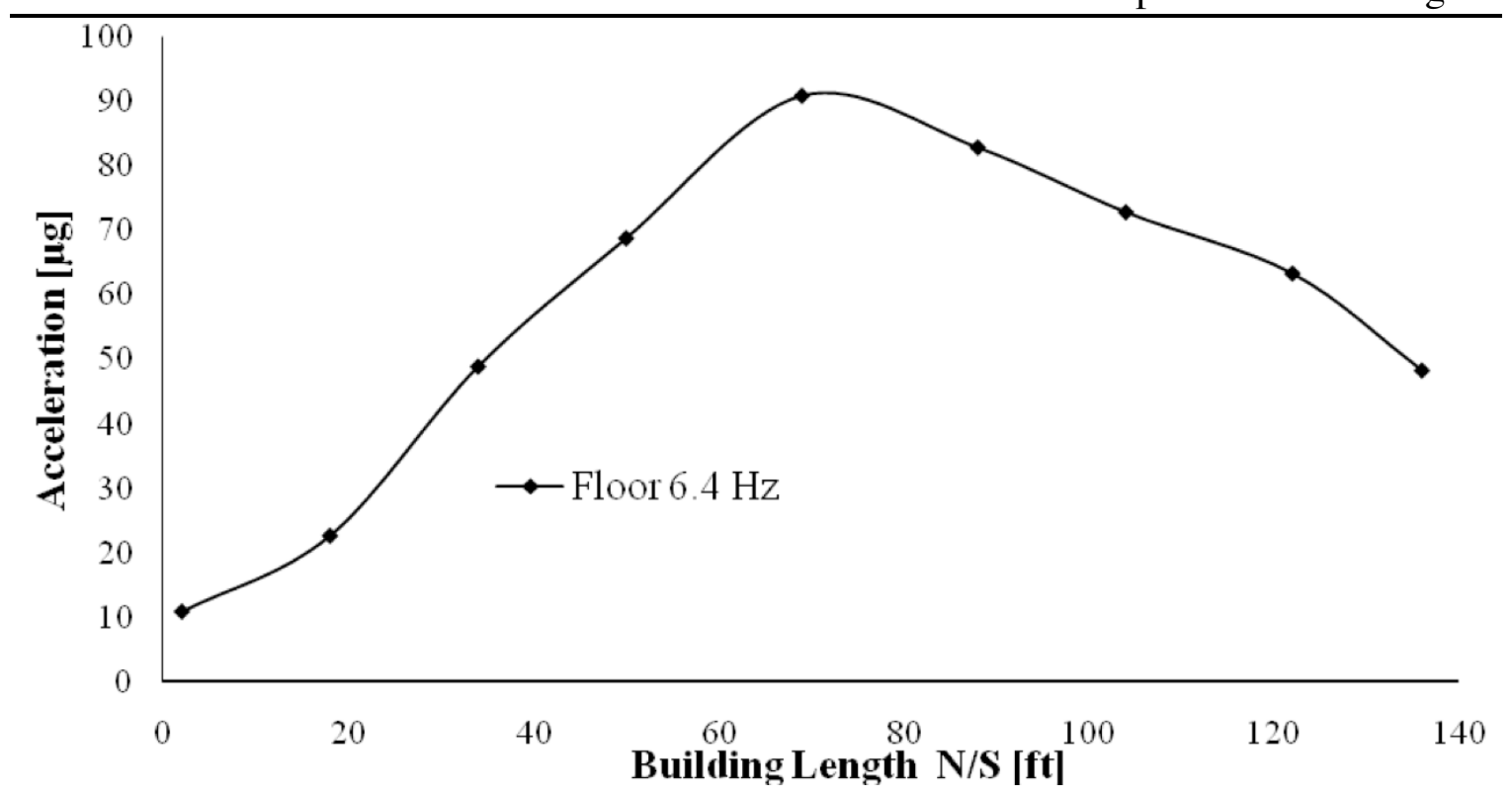

Figure M: EWB Unit 3 Floor Mode Shape at $6.4 \mathrm{~Hz}$

Similar to EWB Unit 5, the mode shape appears to suggest that the floor

diaphragm does not have rigid behavior. The north (or in this case, left) edge of the diaphragm occurs at approximately $20^{\prime}$. At the north edge of the diaphragm the response is approximately $15 \%$ the response at the center of the diaphragm and the response at the south edge of the diaphragm the response is approximately $50 \%$ the response at the center of the diaphragm. The rotations vary across the length of the diaphragm as well, as seen in Table 4 below.

\section{Table 4. EWB Unit 3 Floor Diaphragm Rotations}

\begin{tabular}{|c|c|}
\hline Distance from Left End & Rotation $\left[\mathrm{rad} / \mathrm{s}^{2}\right]$ \\
\hline $10^{\prime}$ & 24.0 \\
\hline $40^{\prime}$ & 40.7 \\
\hline $70^{\prime}$ & 15.8 \\
\hline $100^{\prime}$ & 23.4 \\
\hline $130^{\prime}$ & 48.2 \\
\hline
\end{tabular}

The rotational response varies considerably across the length of the diaphragm, similar to EWB Unit 5. Again, this response suggests that the diaphragm does not have 
Experimental Testing 23

rigid behavior. Unlike EWB Unit 5, however, the rotation recorded at the north edge of EWB Unit 3 was lower than a response closer to the center of the building, unlike EWB Unit 5. This behavior and the low translational response at the north edge of the building can be explained due to the interaction of the building's edge and the building adjacent to it. This interaction will be discussed later in the thesis.

\subsubsection{Building Mode Shape}

The mode shape of the $3^{\text {rd }}$ floor of the CM Building was mapped along the north side of the diaphragm. The results are displayed in Figure $\mathrm{N}$ below.

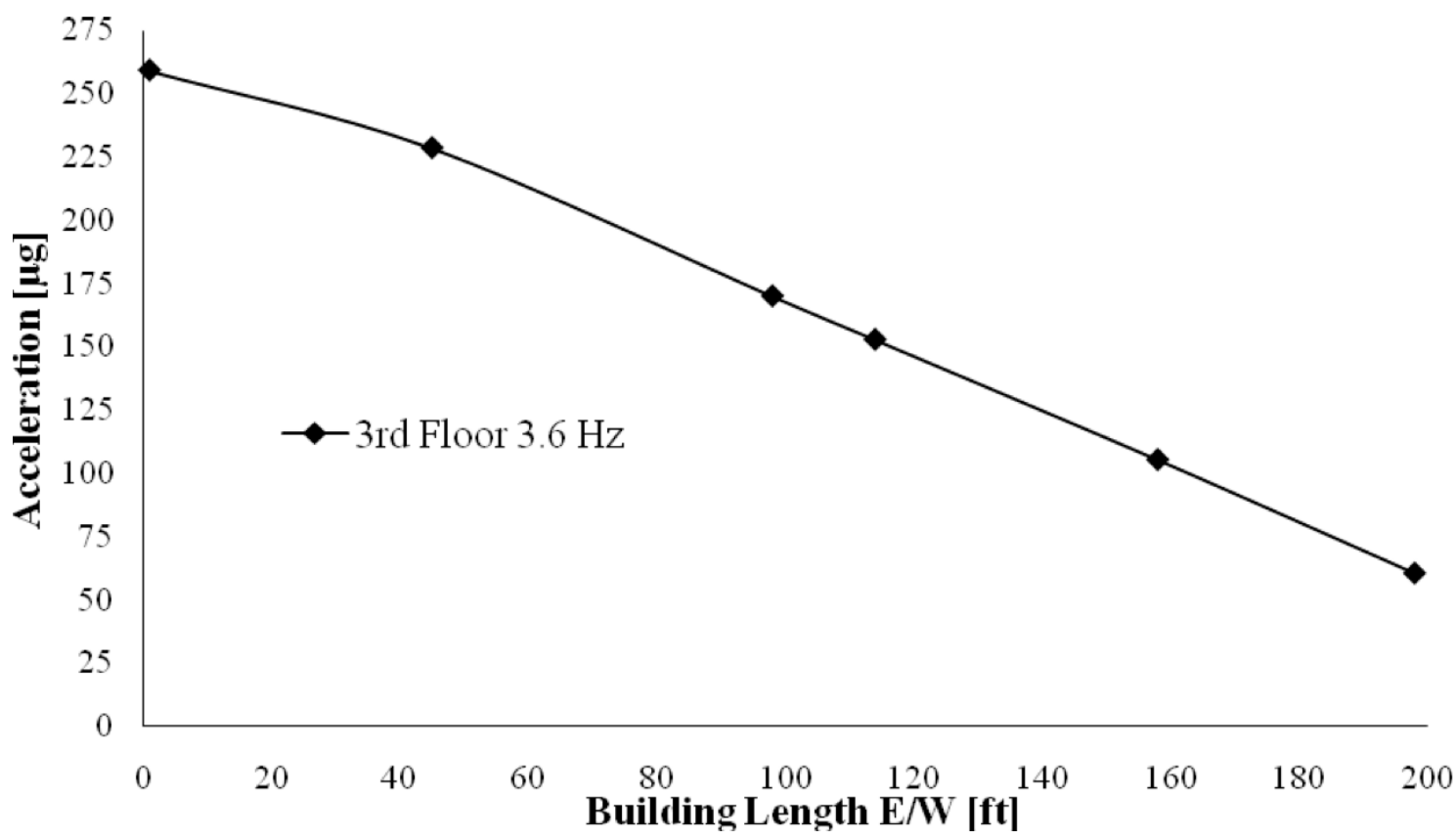

Figure N: CM Building 3rd Floor NS Mode Shape at 3.61 Hz

The above plot shows the acceleration response of the floor diaphragm at several

points along the diaphragm. The response decreases approximately linearly from the west to the east along the length of the diaphragm. This linear relationship suggests that the diaphragm is rigid. The rotation at each of these points was also recorded to determine 
Experimental Testing 24

how uniform the response of the diaphragm was across its length, as seen in Table 5

below.

Table 5. CM Building Floor Rotations

Distance from Left End Rotation $\left[\mathrm{rad} / \mathrm{s}^{2}\right]$

\begin{tabular}{|c|c|}
\hline $10^{\prime}$ & 7.2 \\
\hline $100^{\prime}$ & 35.1 \\
\hline $150^{\prime}$ & 26.2 \\
\hline $180^{\prime}$ & 27.1 \\
\hline
\end{tabular}

The rotational readings along the length of the diaphragm are fairly constant except for the rotation nearest the west edge of the building. Similar to EWB Unit 3, the low rotation value at the extreme edge of the building can be explained by the interaction between the building's edge and the building adjacent to it. Further investigation of this response will be conducted later in the thesis in Section 5.3 starting on page 50 . 
Computational Analysis and Comparison 25

\subsection{COMPUTATIONAL ANALYSIS AND COMPARISON}

The three buildings were all modeled using the commercial computer analysis software ETABS (CSI 2008). The software was used to determine the modal frequency and mode shapes of each structure. The results for the modal frequencies are displayed next to those obtained from the experiment, and the results for the mode shapes are plotted with a dashed line representing the experimental results for comparison.

A load take off was performed to estimate the mass of each building. The mass used in the model greatly affected the modal parameter output. Therefore, it was very important to make as accurate an approximation as possible of the building weight. For each building, the concrete floor and roof diaphragms, beams, walls, cladding, and an approximation of 20 psf for MEP and miscellaneous additional weight were included. A previous student's senior project with a very detailed dead load take-off was consulted in determining the mass of the CM Building (Foschaar 2008). The mass was lumped to each respective floor and roof diaphragm as a uniformly distributed area mass.

The floor and roof diaphragms of each building were modeled based on their gross section properties. Both the decrease in stiffness associated with cracking of the concrete was neglected and the increased strength of the concrete due to hardening overtime were neglected because they are unknowns and affect the concrete stiffness conversely. It was assumed that the two variables counteract each other and it was therefore assumed justifiable to use the gross section properties to determine stiffness.

Based on the experimental results obtained for the mode shapes of EWB Unit 5 and EWB Unit 3 their diaphragms were initially modeled as semi-rigid. The semi-rigid 
Computational Analysis and Comparison 26

diaphragm designation causes the stiffness of the diaphragm to be determined based on the properties assigned to the slab. The experimental results for the CM Building's mode shape suggested that the diaphragm was rigid; therefore the diaphragm in the computational model was initially assigned to be rigid. For comparison purposes, each building was modeled with both rigid and semi-rigid diaphragm assignments.

Only the lateral force resisting elements of each structure were included in the computational model. Any additional structural and non-structural elements were omitted because their effect on the dynamic response of the structure was minimal.

\subsection{EWB Unit 5 Computational Model}

A screen shot of the EWB Unit 5 computer model is shown in Figure P below.

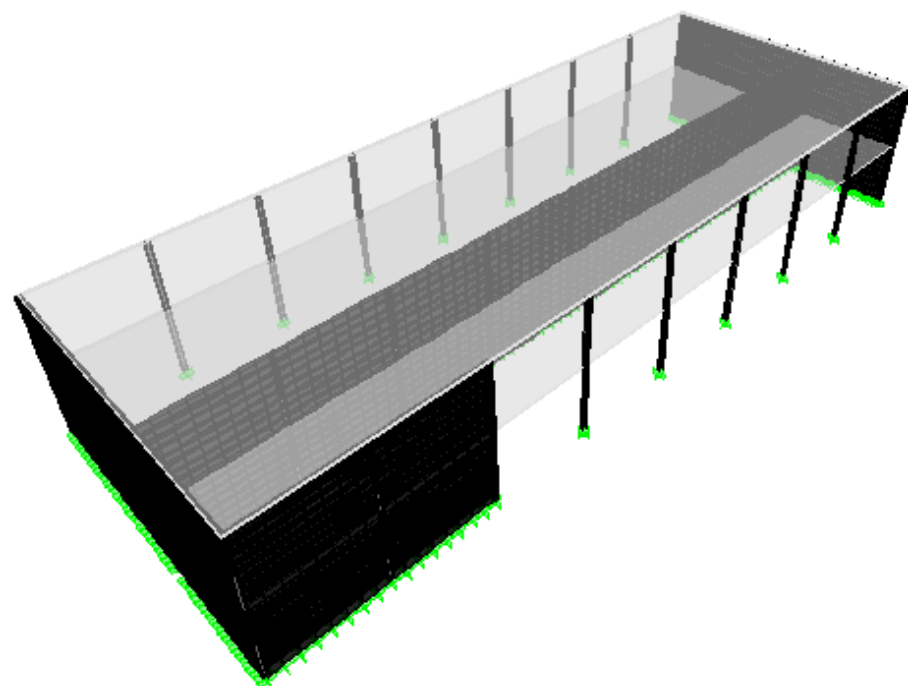

Figure P: EWB Unit 5 Computer Generated Model

The north-south running brick shear walls at the east and west sides of the

building were modeled as solid brick walls with a modulus of elasticity of $1050 \mathrm{ksi}$ and

Poisson's ratio of 0.2. This assumption for the modulus of elasticity is based off the MSJC code provision and an assumed f'm of 1500 psi (MSJC). The grout between the 
Computational Analysis and Comparison 27

two withes of brick was assumed to have the same material properties as the brick surrounding it.

When EWB Unit 5 was modeled with a rigid diaphragm at the floor and roof the results for the modal periods did not match the experimental results. The first mode was found to be in the north-south direction and the second mode in the east-west direction. This evidence, along with the flexible behavior of the diaphragms in the experimental testing, drove the decision to define the diaphragms as semi-rigid. The semi-rigid diaphragm designation resulted in the first two building modes occurring in the northsouth direction, matching the experimental results. The results for the first two modal periods based on the computational model and the experimental results are found in Table 6 below.

Table 6. Comparison of Modal Frequencies for EWB Unit 5 [Hz]

\begin{tabular}{|c|c|c|c|}
\cline { 2 - 4 } \multicolumn{1}{c|}{} & Experiment & Semi-Rigid & Rigid \\
\hline Mode 1 & 5.3 & 5.25 & 9.33 \\
\hline Mode 2 (4) & 9.25 & 6.9 & 25.5 \\
\hline
\end{tabular}

The first modal frequency for the semi-rigid diaphragm designation is very similar to the experimental result, but the second mode from the semi-rigid results is much lower. Modifying the out-of-plane thickness of the wall by a factor of 2.6 produced a second modal frequency value of $9.2 \mathrm{~Hz}$. The first mode remained unchanged with the modified out-of-plane thickness. This modification points to the discrepancy being an issue related to the out-of-plane stiffness of the full height shear wall that runs the length of the building, but a full explanation could not be found. The computational model produced results for the modal frequencies that are very close to the experimental results when assigning a semi-rigid diaphragm to the floor and roof of EWB Unit 5. Assigning An Investigation of the Influence of Diaphragm Flexibility on Building Design through a Comparison of Forced Vibration Testing and Computational Analysis 
Computational Analysis and Comparison 28

the diaphragms as rigid grossly overestimates the modal frequencies and the second North-South mode is the fourth mode rather than the second.

The mode shape for the floor and roof were also determined from the computational model. The units of the mode shapes that were determined by the experiment and computational model are different. Therefore, in order to compare the mode shapes determined experimentally with those determined computationally the mode shapes were mass orthonormalized (Humar 1990). The equation used for mode shape mass orthonormalization is

$$
\frac{\Phi}{\sqrt{\Phi^{T} * M * \Phi}},
$$

where $\Phi$ represents the mode shape, and $M$ represents the mass matrix.

The mode shapes for the floor are found on the plot in Figure Q below and Figure $\mathrm{R}$ on the next page.

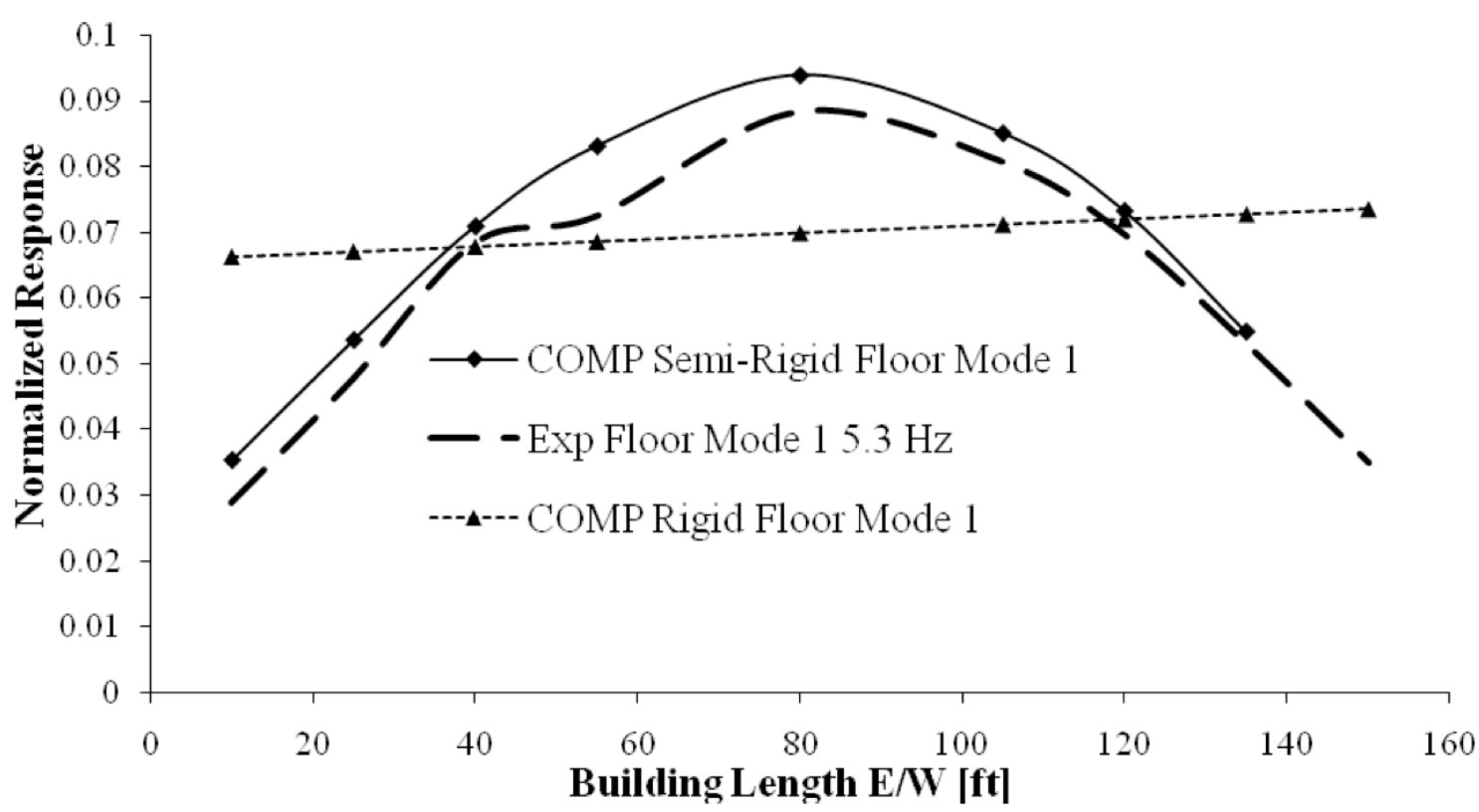

Figure Q: EWB Unit 5 Computational Floor $1^{\text {st }}$ Mode Shape \& Experimental

An Investigation of the Influence of Diaphragm Flexibility on Building Design through a Comparison of Forced Vibration Testing and Computational Analysis 
Computational Analysis and Comparison 29

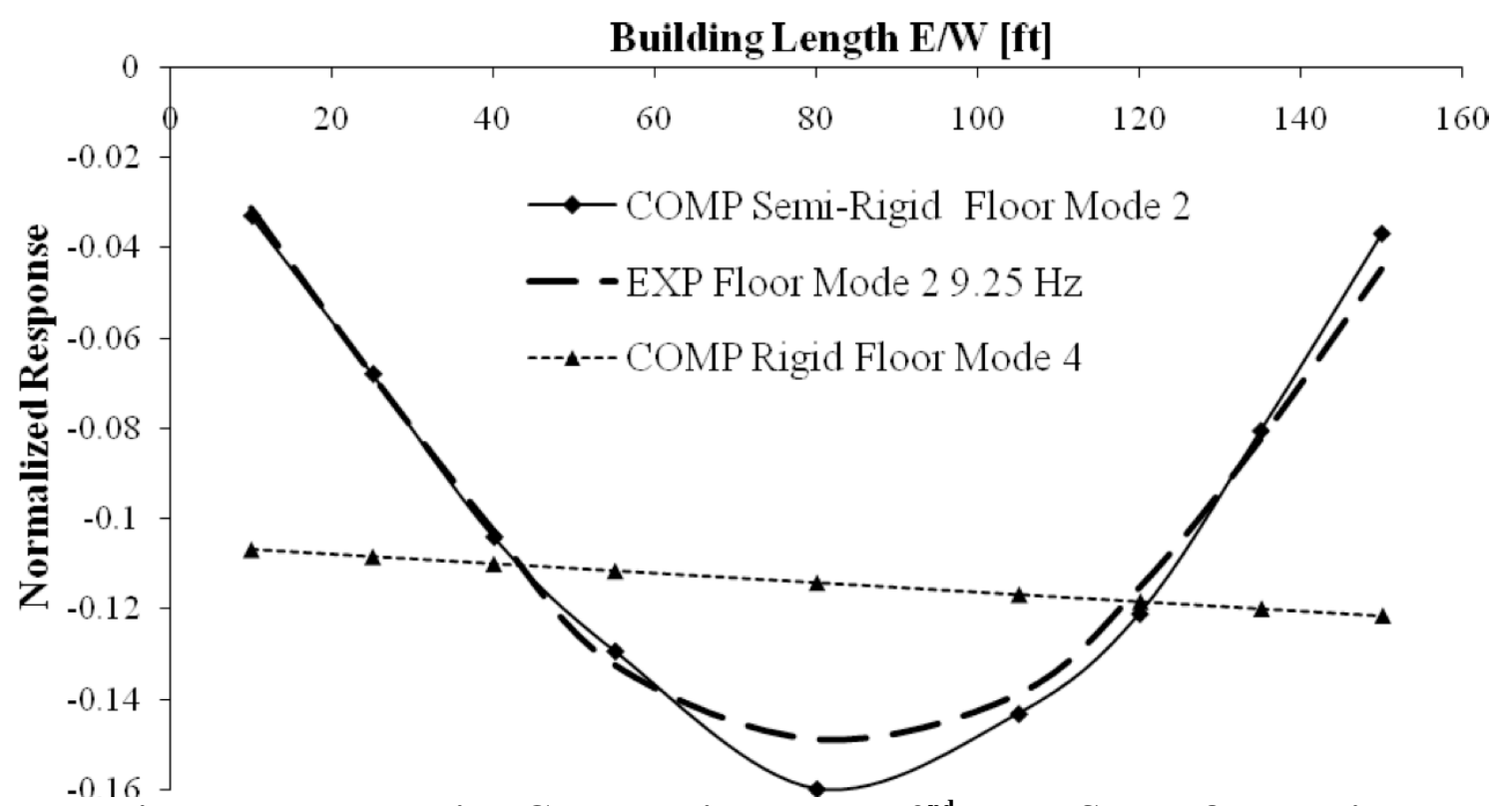

Figure R: EWB Unit 5 Computational Floor $2^{\text {nd }}$ Mode Shape \& Experimental

The roof mode shapes are similar to those shown above for the floor. Each mode shape is orthonormalized. The semi-rigid computational mode shapes are very similar to the experimental mode shape results with the exception of some dips in the experimental plot. This discrepancy can be attributed to ambient accelerations that were included in the responses obtained from the experiment. The ambient vibrations caused fluctuations in the acceleration responses of up to $20 \mu \mathrm{g}$. The mode shape for the computational model assigned with a rigid diaphragm is shown for comparison and is clearly not similar to the experimentally determined mode shape. Clearly the computational results more closely match the experimental results when the diaphragm is assigned to be semi-rigid rather than rigid.

To more precisely compare how closely two mode shapes match, the modal assurance criterion (MAC) was used (Allemang 2003). A comparison of the MAC numbers for each mode, both rigid and semi-rigid, shows the difference in accuracy 
Computational Analysis and Comparison 30

between the two diaphragm designations. The MAC number is a comparison of the similarity of two mode shapes and is determined by the equation

$$
\frac{\left(\Phi_{E X P}^{T} * M * \Phi_{C O M P}\right)}{\left(\Phi_{E X P}^{T} * M * \Phi_{E X P}\right) *\left(\Phi_{C O M P}^{T} * M * \Phi_{C O M P}\right)},
$$

where $\Phi_{E X P}$ represents the experimentally determined mode shape, $\Phi_{\text {COMP }}$ represents the computationally determined mode shape, and $M$ represents the mass matrix.

A MAC number of 1 indicates perfect correlation between the mode shapes. The typical MAC number equation, in this case, is modified by adding a weight factor (the mass matrix). The mode shapes are weighted so that mode shapes that contain both translational and rotational accelerations with different units can be used in the equation (McDaniel and Archer 2010). Table 7 below displays the results for the mass weighted MAC numbers for both modes. The table compares the experimental results to both the semi-rigid diaphragm computational model and the rigid diaphragm computational model.

\section{Table 7. Comparison of MAC Numbers for EWB Unit 5}

\begin{tabular}{|l|c|c|}
\cline { 2 - 3 } \multicolumn{1}{c|}{} & Semi-Rigid & Rigid \\
\hline Mode 1 & 0.997 & 0.938 \\
\hline Mode 2 & 0.995 & 0.866 \\
\hline
\end{tabular}

The MAC numbers for the semi-rigid diaphragm computational model are nearly 1 and much more accurate than the rigid diaphragm results. To ensure that the computational models were performing similarly to the experimental results the vertical mode shape was also determined from both computational models. Figure $S$, on the next page, shows the mode shape's vertical elevation view for the first and second mode. 
Computational Analysis and Comparison 31

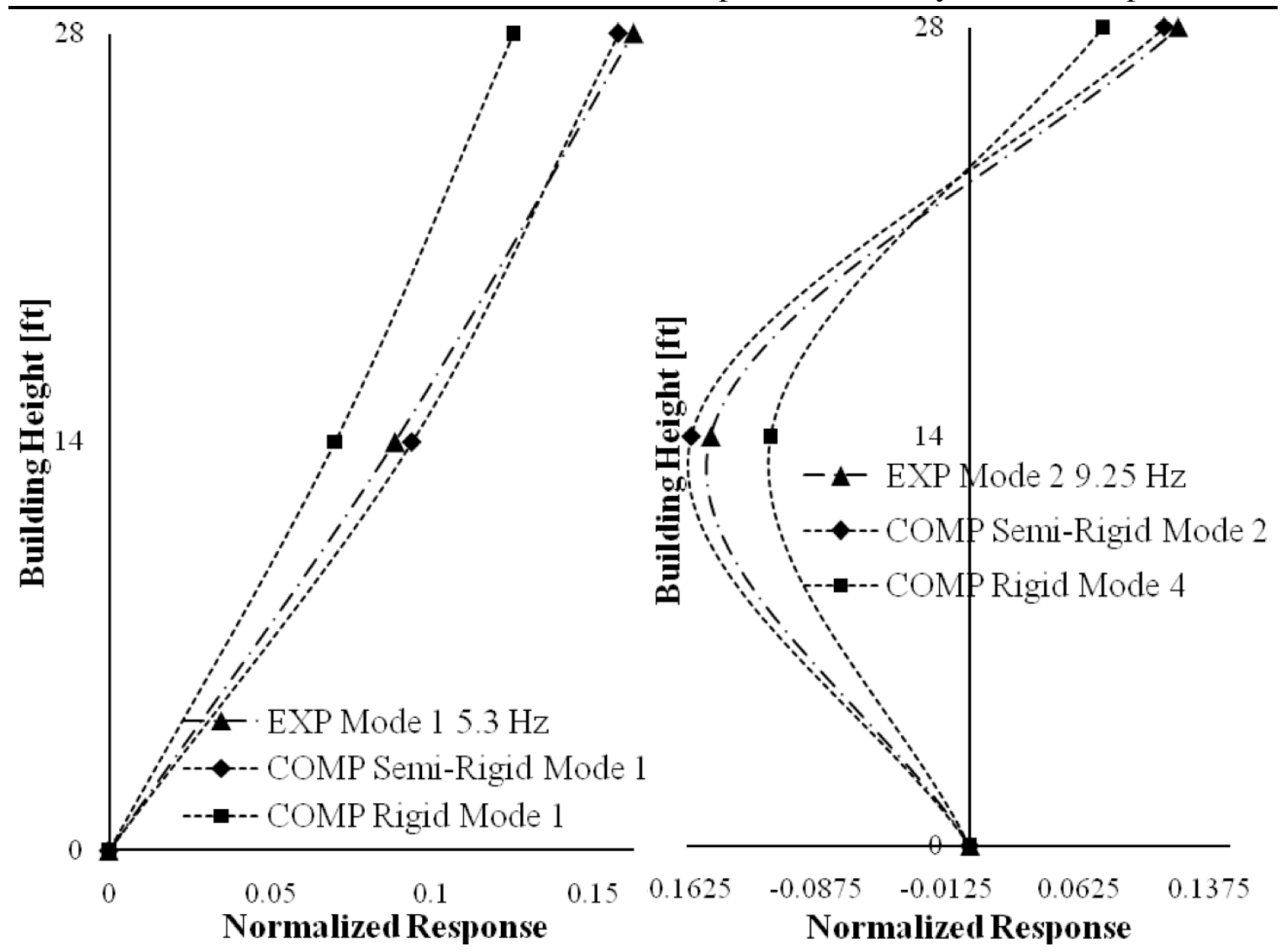

Figure S: EWB Unit 5 Computational Vertical Mode Shape 1 and 2

The vertical mode shapes of the computational model show that the first two north-south modes from the semi-rigid and rigid model are both in the north-south direction, similar to the experimental results. In the first mode the floor and roof deform in-phase and in the second mode the floor and roof deform out-of-phase.

The plots for the mode shapes show that the computational model results for the semi-rigid diaphragm closely corresponded to the experimental results. It is concluded that it is most accurate to assign the diaphragm in the computational model to be semirigid to accurately mimic the physical response of the structure. It is inaccurate to idealize the diaphragm as rigid, in this case.

\footnotetext{
An Investigation of the Influence of Diaphragm Flexibility on Building Design through a Comparison of Forced Vibration Testing and Computational Analysis
} 
Computational Analysis and Comparison 32

\subsection{EWB Unit 3 Computational Model}

A screen shot of the EWB Unit 3 computer model is shown in Figure T below.

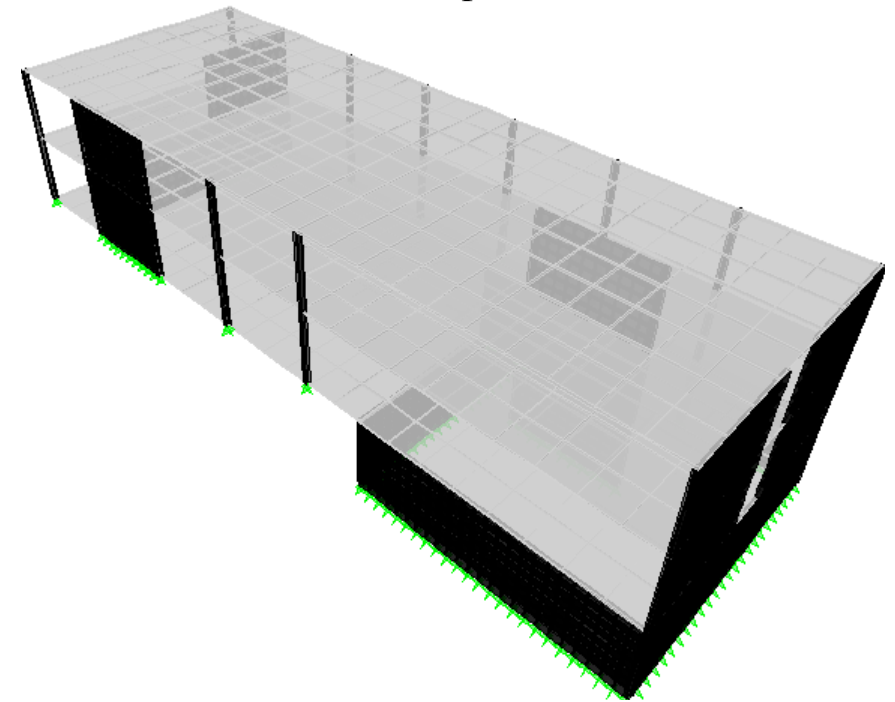

Figure T: EWB Unit 3 Computer Generated Model

EWB Unit 3 has a basement that is only under the south half of the building. It was modeled because the shear walls in the basement affected the stiffness of the super structure. Therefore, the model has a first floor and roof diaphragm and a rigid diaphragm at the top of the basement level. Similar to EWB Unit 5, EWB Unit 3 was first modeled with a rigid diaphragm designation. The modes that resulted from the rigid diaphragm designation were not as accurate as when the diaphragm was assigned to be semi-rigid. The results for the first modal frequencies for the computational model compared to the experiment are found in Table 8 below.

\section{Table 8. Comparison of Modal Frequencies EWB Unit 3 [Hz]}

\begin{tabular}{|l|c|c|c|}
\cline { 2 - 4 } \multicolumn{1}{c|}{} & Experiment & Semi-Rigid & Rigid \\
\hline Mode 1 EW & 6.4 & 5.7 & 8.6 \\
\hline Mode 2 NS & 5.3 & 7.0 & 6.7 \\
\hline
\end{tabular}

The interaction between EWB Unit 3 and the adjoining buildings may have caused the computational and experimental frequency results not to match as well as they could have. The order of the modal frequencies determined from the computational An Investigation of the Influence of Diaphragm Flexibility on Building Design through a Comparison of Forced Vibration Testing and Computational Analysis 
Computational Analysis and Comparison 33

model is opposite to that found from the experiment. One explanation for this swapping of modes may be the influence of the seismic joint connection at the edges of the building and the flexibility of the soil at the base of the shear walls. See Section 5.3 starting on page 49 of this thesis for a discussion on the modeling of the seismic joints and the interaction of EWB Unit 3's building edge to the adjacent buildings. Further research needs to be done to determine the true impact of the soil flexibility on the stiffness of the building in the north-south direction. The soil was not modeled; however, a more flexible soil would cause the north-south frequency to decrease. The frequency in the east-west direction would remain similar to the computationally determined value because of the restraint and added stiffness caused by the connection to the adjacent buildings that run perpendicular to EWB Unit 3 balancing the added flexibility from the soil. The floor mode shape from the computational model for EWB Unit 3 is seen in Figure U, below.

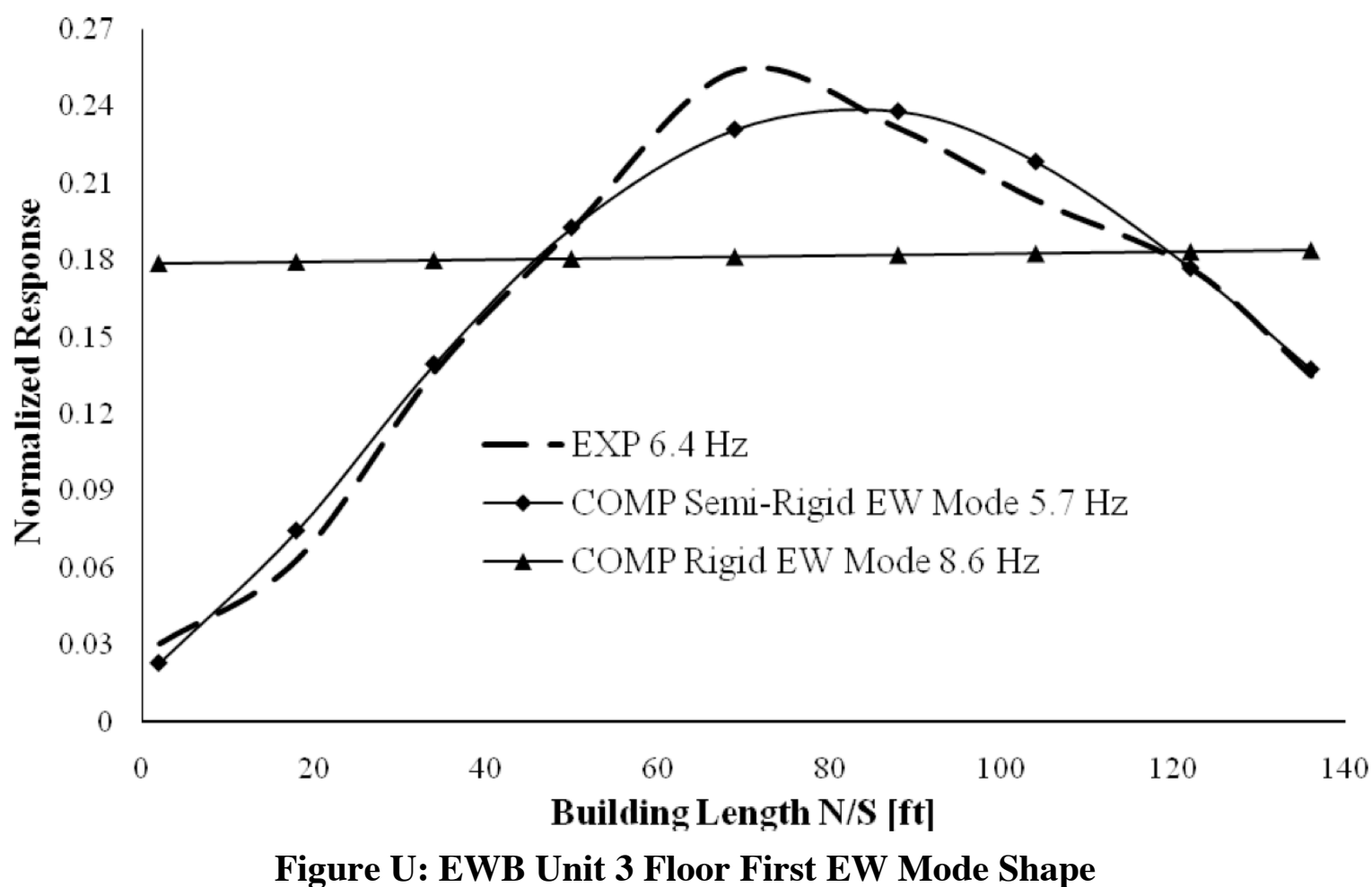

An Investigation of the Influence of Diaphragm Flexibility on Building Design through a Comparison of Forced Vibration Testing and Computational Analysis 
Computational Analysis and Comparison 34

The maximum deformation of the floor diaphragm occurs at approximately 80

feet. The semi-rigid computational results for the mode shape similarly match the experimental results from EWB Unit 5. Again, the ambient vibration caused slight increases and decreases in the experimentally determined mode shape accelerations. The semi-rigid computational model is clearly more similar to the experimental results than the rigid computational results. The MAC numbers for EWB Unit 3 are displayed in Table 9 below.

\section{Table 9. Comparison of MAC Numbers for EWB Unit 3}

\begin{tabular}{|c|c|c|}
\cline { 2 - 3 } \multicolumn{1}{c|}{} & Semi-Rigid & Rigid \\
\hline Mode 1 EW & 0.996 & 0.864 \\
\hline
\end{tabular}

The MAC numbers show that the semi-rigid computational model produces results for the mode shape that are more similar to the experimental results than the rigid computational model. The MAC number for EWB Unit 3 is almost identical to EWB Unit 5. The semi-rigid computational model is a more accurate representation of the physical building response than the rigid computational model.

\subsection{Building Computational Model}

A screen shot of the CM Building computer model is shown in Figure V on the next page.

An Investigation of the Influence of Diaphragm Flexibility on Building Design through a Comparison of Forced Vibration Testing and Computational Analysis 


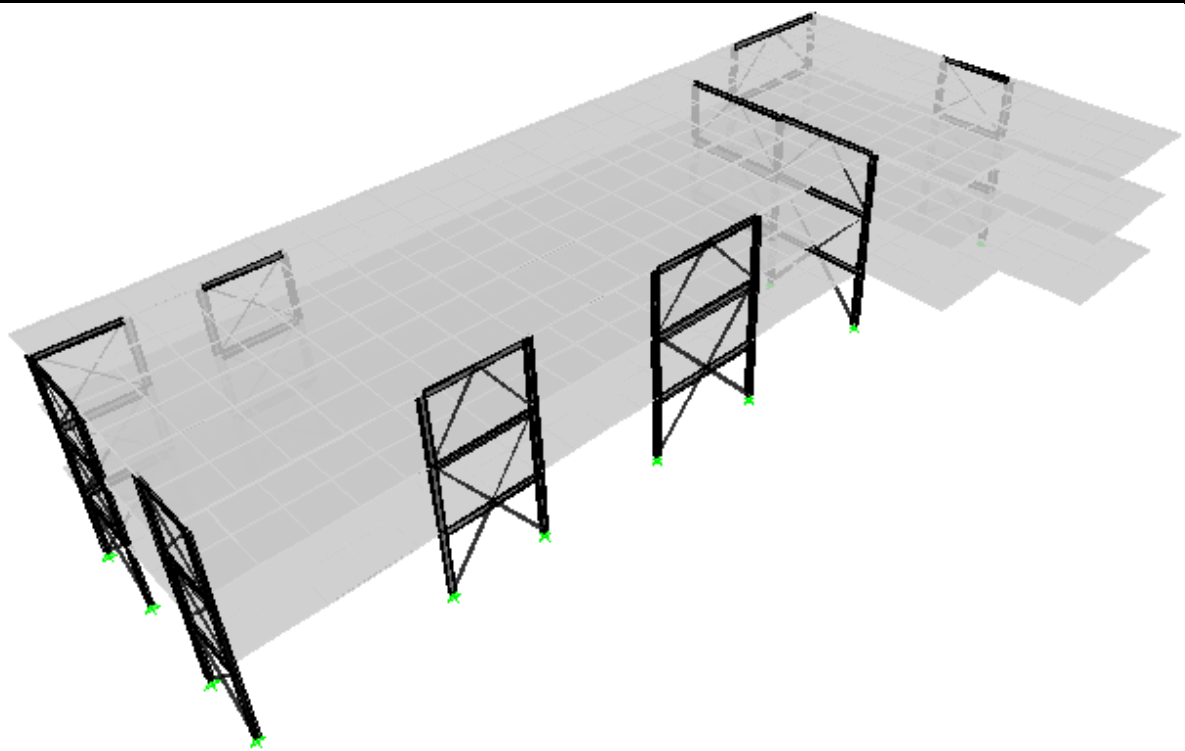

Figure V: CM Building Computer Generated Model

The experimental results suggested that the CM Building had a rigid diaphragm.

Therefore, the floors and roof were assigned a rigid diaphragm. The results for the modal periods of vibration were higher than those obtained from experimental testing. The results for the first two modal frequencies from the computational model for the $\mathrm{CM}$ Building are listed along with the experimental results in Table 10 below.

Table 10. Comparison of CM Building Modal Frequencies [Hz]

\begin{tabular}{|c|c|c|c|}
\cline { 2 - 4 } \multicolumn{1}{c|}{} & Experiment & Rigid & Semi-Rigid \\
\hline Mode EW & 3.95 & 2.3 & 2.2 \\
\hline Mode NS & 3.61 & 2.6 & 2.4 \\
\hline
\end{tabular}

The disparity in results between computational analysis and experimental testing exists because of one or both of two issues; the mass is being overestimated or the stiffness is being underestimated. The problem is probably not the mass estimation because even when only the weight of the floor and roof decks are considered in the building weight, the modal frequencies determined by the computational model are still lower (approximately $2.60 \mathrm{~Hz}$ east-west and $2.88 \mathrm{~Hz}$ north-south) than those determined through the experimental testing. This consideration points to a problem with how the An Investigation of the Influence of Diaphragm Flexibility on Building Design through a Comparison of Forced Vibration Testing and Computational Analysis 
Computational Analysis and Comparison 36 stiffness of the CM Building was modeled. As can be seen in Figure V of the previous page, only the elements of the lateral force resisting system were modeled in the structure. On the exterior façade of the CM Building there are large concrete blocks hung as cladding. This cladding may be adding a considerable amount of stiffness to the structure when excited at low energy levels. Additionally, when the stiffness attributed to the concrete cladding is not included, the first two modal frequencies are out of order in comparison to the experimental results (as seen in Table 10, page 35). The difference between the modal frequencies for the rigid and semi-rigid diaphragm designations was less dramatic for the CM Building. Unlike the other two buildings the CM Building diaphragm designation did not have a significant effect on the modal frequencies.

The mode shape for the 3rd floor of the CM Building was also determined from the computational model. The mode shape is found in Figure W below.

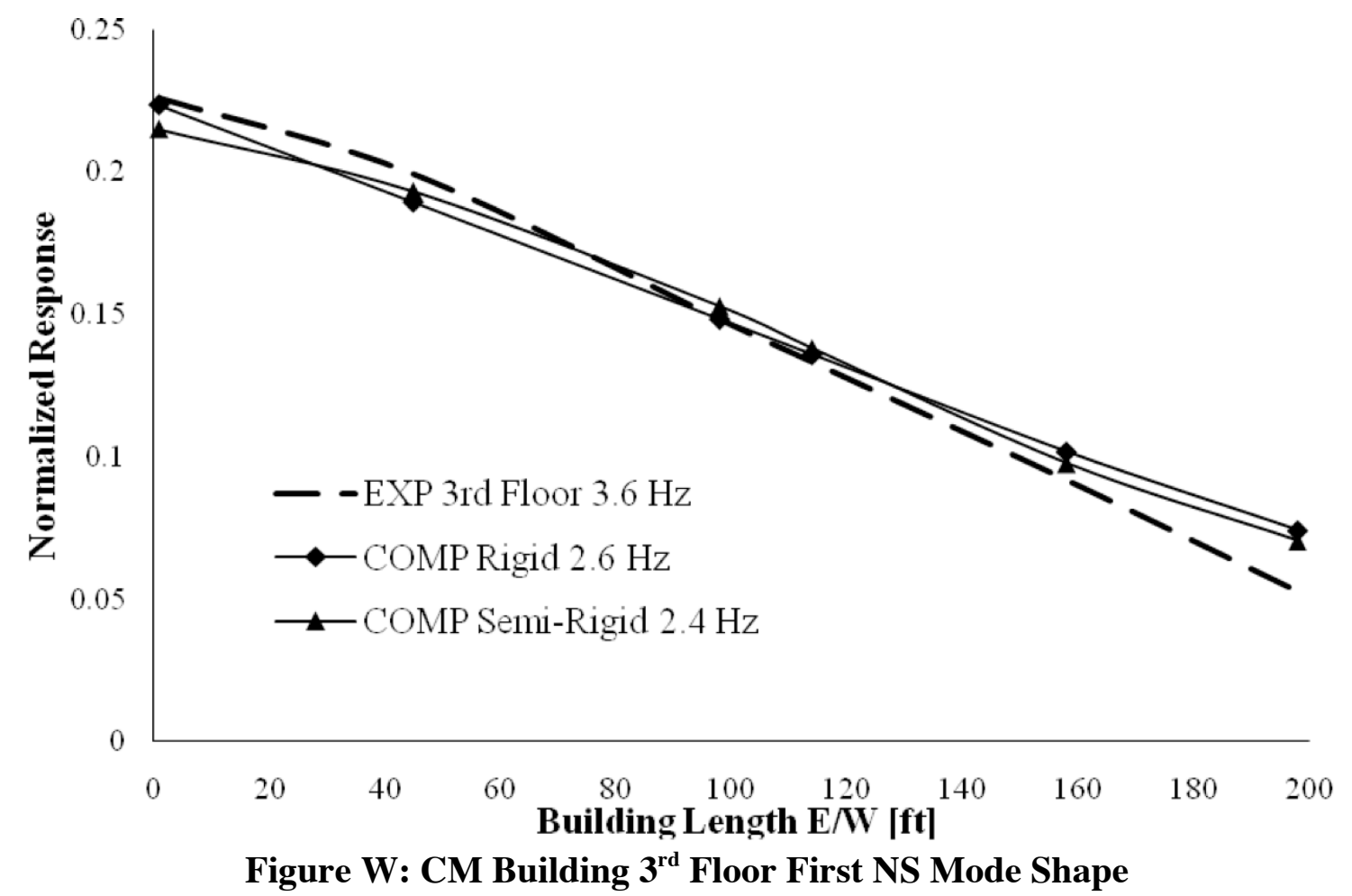

An Investigation of the Influence of Diaphragm Flexibility on Building Design through a Comparison of Forced Vibration Testing and Computational Analysis 
Computational Analysis and Comparison 37

The maximum deformation occurs at the west edge of the building and decreases approximately linearly to the east edge of the building. The mode shapes from both the semi-rigid and rigid computational models are very similar to the experimentally determined mode shape. Further evidence of the similarity between the mode shapes determined from the computational model and the experimental results is seen by examining their MAC numbers. The MAC numbers for both the semi-rigid and rigid computational models are found in Table 11 below.

Table 11. Comparison of MAC Numbers for CM Building

\begin{tabular}{|c|c|c|}
\cline { 2 - 3 } \multicolumn{1}{c|}{} & Semi-Rigid & Rigid \\
\hline Mode NS & 0.996 & 0.995 \\
\hline
\end{tabular}

The similarity in mode shapes and the high value for the MAC numbers in the semi-rigid and rigid computational models suggest that the CM Building floor diaphragms are approximately rigid. It can be concluded that idealizing the diaphragm as rigid in the computational model is a valid assumption when performing a computational analysis of the CM Building.

An Investigation of the Influence of Diaphragm Flexibility on Building Design through a Comparison of Forced Vibration Testing and Computational Analysis 
Design Implications 38

\subsection{DESIGN IMPLICATIONS}

In section 3.0 it was shown that the floor diaphragms for the three buildings investigated are not all rigid as the ASCE 7-05 code allows the designer to assume. This section will investigate the influence that idealizing each building diaphragm as rigid has on the overall design of each building.

The assignment of the diaphragm as rigid or semi-rigid in the computational model had an affect on the modal periods, as shown in the previous section. It is important to make a proper estimate of a building period in order to approximate the accelerations that the building will undergo in the Design Basis Earthquake (DBE). In ASCE 7-05 a response spectrum is determined based on the location of the building site, soil conditions, and 2/3 of the Maximum Considered Earthquake (MCE). The design response spectrum for the site and soil conditions for the three buildings under investigation is seen in Figure $\mathrm{X}$ below.

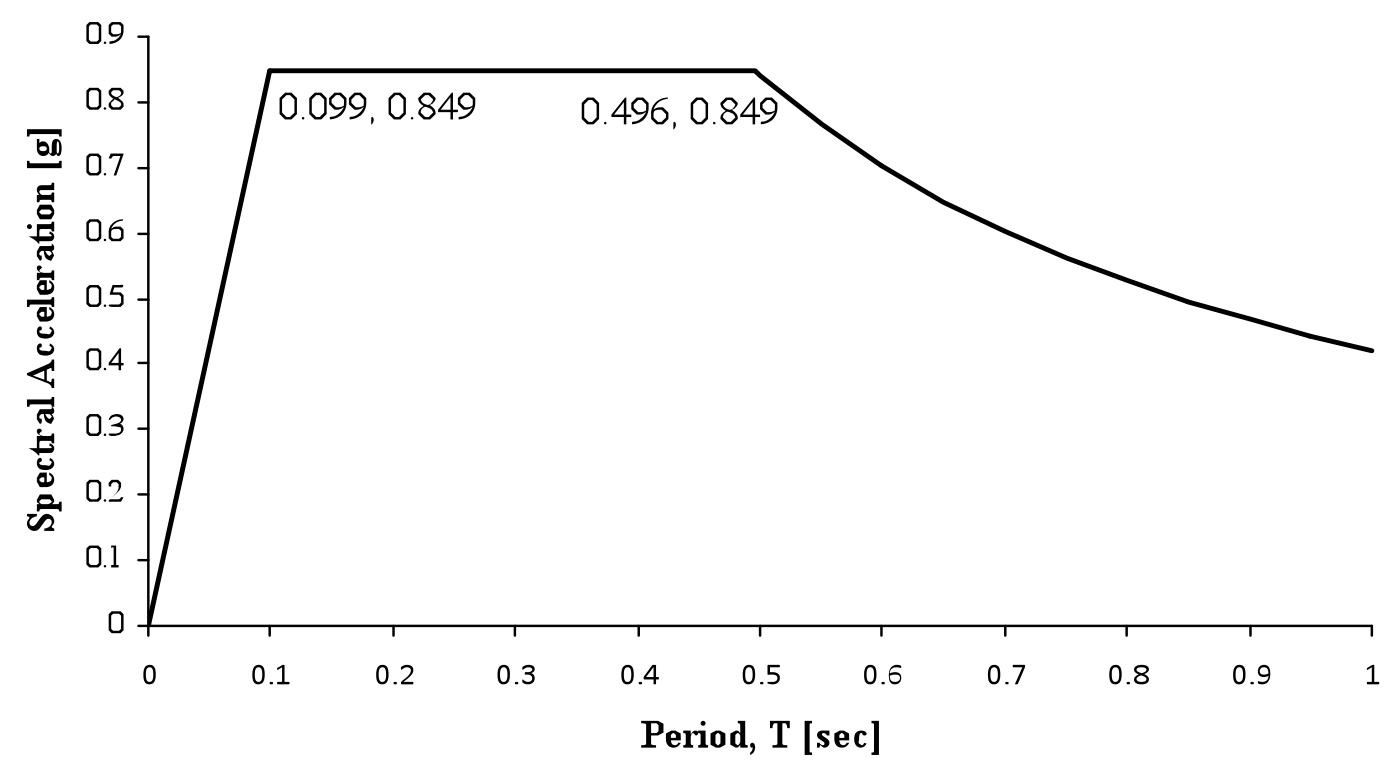

Figure X: ASCE 7-05 Design Response Spectrum

\footnotetext{
An Investigation of the Influence of Diaphragm Flexibility on Building Design through a Comparison of Forced Vibration Testing and Computational Analysis
} 
Design Implications 39

According to the ASCE 7-05 design response spectrum, the periods for all three buildings with both semi-rigid and rigid diaphragm designations fall on the response spectrum plateau and thus have the same spectral response acceleration. For the purposes of this thesis the forces and displacements were not adjusted by the ' $R$ ' and $C_{d}$ ' factors because only a comparison of the difference between the results obtained from the semirigid and rigid computational models was made.

Another method for determining the design ground acceleration of a building is to perform a response spectrum analysis with a number of different earthquake records. The SAC project, a joint venture of the Structural Engineers Association of California (SEAOC), the Applied Technology Council (ATC), and California Universities for Research in Earthquake Engineering (CUREe), compiled a list of twenty earthquake records for the purpose of performing a response spectrum analysis for their project (SAC 1994) (FEMA 355C 2000). An average of the earthquake records' response spectra was taken to produce a single curve to determine spectral accelerations for the buildings examined in this thesis. A trend line was then set to the curve to determine spectral accelerations at any point on the curve. The equation for the trend line is seen on the plot. A plot of the average of the SAC earthquake response spectra is seen in Figure $\mathrm{Y}$ on the next page. 


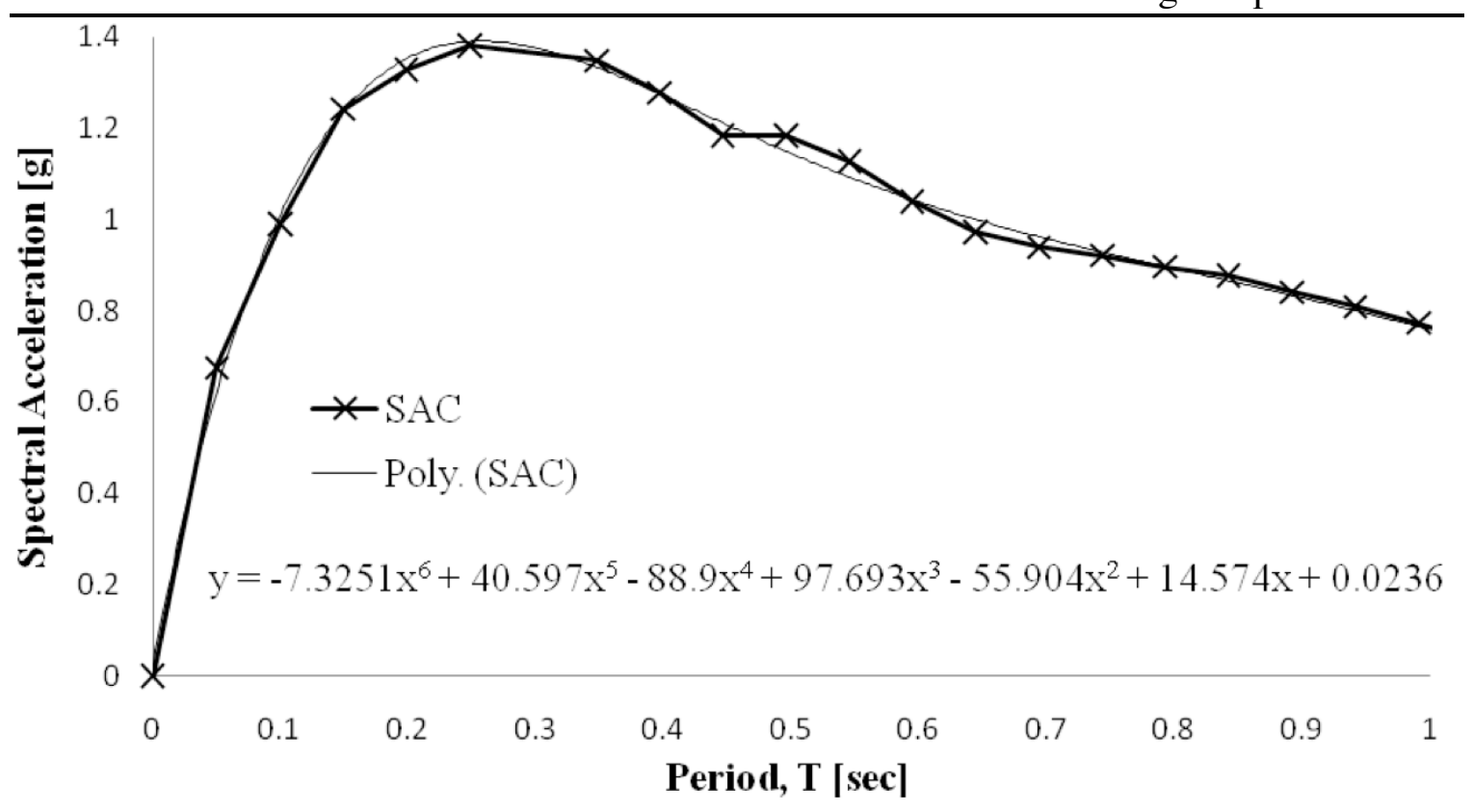

Figure Y: SAC Averaged Response Spectra with Trend Line

From the accelerations determined by both ASCE and SAC the base shear and lateral force resisting element design forces were compared for the semi-rigid and rigid diaphragm computational models. It is important to note that the accelerations and forces determined by the ASCE 7-05 design response spectrum cannot be compared directly to the SAC response spectra. The SAC ground motions were not scaled to the building sites. The comparisons made are strictly based on the percent change of the accelerations, forces, and displacements between the semi-rigid and rigid computational models.

The results of the comparisons for the periods, acceleration, base shear, wall shear forces, roof displacement, and max story drift are summarized in Table 12 on the next page and Table 13 on page 43.

\footnotetext{
An Investigation of the Influence of Diaphragm Flexibility on Building Design through a Comparison of Forced Vibration Testing and Computational Analysis
} 
Table 12. ASCE7-05 Comparison of Design Parameters

\begin{tabular}{|c|c|c|c|}
\hline \multicolumn{2}{|c|}{ EWB UNIT 5 } & \multirow{2}{*}{} \\
\cline { 1 - 3 } & Rigid & Semi-Rigid & Difference \\
\hline Period [sec] & 0.11 & 0.19 & $79 \%$ \\
\hline Acceleration [g] & 0.85 & 0.85 & $0 \%$ \\
\hline Base Shear [k] & 2794 & 2794 & $0 \%$ \\
\hline SW Force [k] & 1284 & 1203 & $-6 \%$ \\
\hline Roof Displacement [in] & 0.116 & 0.443 & $282 \%$ \\
\hline Max Story Drift & 0.00039 & 0.0016 & $324 \%$ \\
\hline
\end{tabular}

\begin{tabular}{|c|c|c|c|}
\hline \multicolumn{3}{|c|}{ EWB UNIT 3 } & \multirow{2}{*}{} \\
\cline { 1 - 3 } & \multicolumn{2}{|c|}{1881 kips } & \\
\hline Approx Bldg Weight $=$ & Rigid & Semi-Rigid & Difference \\
\hline Period [sec] & 0.12 & 0.17 & $43 \%$ \\
\hline Acceleration [g] & 0.85 & 0.85 & $0 \%$ \\
\hline Base Shear [k] & 1597 & 1597 & $0 \%$ \\
\hline North SW Force [k] & 672 & 645 & $-4 \%$ \\
\hline South SW Force [k] & 592 & 577 & $-3 \%$ \\
\hline Roof Displacement [in] & 0.186 & 0.343 & $84 \%$ \\
\hline Max Story Drift & 0.00058 & 0.0014 & $148 \%$ \\
\hline
\end{tabular}

\begin{tabular}{|c|c|c|c|}
\hline \multicolumn{2}{|c|}{ CM Bldg } & \multicolumn{1}{|c|}{} \\
\cline { 1 - 2 } & \multicolumn{2}{|c|}{3788 kips } & \\
\hline Approx Bldg Weight $=$ & Rigid & Semi-Rigid & Difference \\
\hline Period [sec] & 0.4 & 0.413 & $3 \%$ \\
\hline Acceleration [g] & 0.849 & 0.849 & $0 \%$ \\
\hline Base Shear [k] & 3216 & 3216 & $0 \%$ \\
\hline Brace Force [k] & 1188 & 1237 & $4 \%$ \\
\hline Roof Displacement [in] & 2.88 & 2.91 & $1 \%$ \\
\hline Max Story Drift & 0.0069 & 0.007 & $2 \%$ \\
\hline
\end{tabular}

The base shear did not change in any of the three buildings because the spectral acceleration for the rigid and semi-rigid models was the same. The small decrease in shear wall force in EWB Unit 5 is attributed to the increase in out-of-plane shear that is An Investigation of the Influence of Diaphragm Flexibility on Building Design through a Comparison of Forced Vibration Testing and Computational Analysis 
Design Implications 42

resisted by the walls perpendicular to the loading. EWB Unit 3 saw changes in the shear wall forces because of the force distribution characteristic to rigid and non rigid elements under lateral loading.

Although the base shear and shear wall forces did not change significantly, the change in roof displacement and maximum story drift was more apparent. A more than $300 \%$ increase in the maximum inter story drift of EWB Unit 5 occurred. However, the drift is still well within the limit for brick shear wall buildings. According to ASCE 7-05 Table 12.12-1 the allowable maximum drift for masonry cantilever shear wall structures is $0.010 h_{s x}$. The drift is approximately $10 \%$ of the allowable maximum drift. In a building design where the drift is close to the allowable maximum drift, assuming the diaphragm to be rigid would have more of an impact on the design than in these cases. 
Design Implications 43

Table 13. SAC Comparison of Design Parameters

\begin{tabular}{|c|c|c|c|}
\hline \multicolumn{2}{|c|}{ EWB UNIT 5 } & \multirow{2}{*}{3291 kips } & \\
\cline { 1 - 3 } Approx Bldg Weight $=$ & Rigid & Semi-Rigid & Difference \\
\hline Period [sec] & 0.11 & 0.19 & $79 \%$ \\
\hline Acceleration [g] & 1.05 & 1.34 & $28 \%$ \\
\hline Base Shear [k] & 3456 & 4410 & $28 \%$ \\
\hline SW Force [k] & 1548 & 1845 & $19 \%$ \\
\hline Roof Displacement [in] & 0.14 & 0.686 & $390 \%$ \\
\hline Max Story Drift & 0.000466 & 0.002521 & $441 \%$ \\
\hline
\end{tabular}

\begin{tabular}{|c|c|c|c|}
\hline \multicolumn{3}{|c|}{ EWB UNIT 3} & \multirow[b]{3}{*}{ Difference } \\
\hline Approx Bldg Weight = & \multicolumn{2}{|c|}{1881 kips } & \\
\hline & Rigid & Semi-Rigid & \\
\hline Period [sec] & 0.118 & 0.169 & $43 \%$ \\
\hline Acceleration [g] & 1.11 & 1.29 & $16 \%$ \\
\hline Base Shear [k] & 2088 & 2426 & $16 \%$ \\
\hline North SW Force [k] & 836 & 926 & $11 \%$ \\
\hline South SW Force [k] & 810 & 873 & $8 \%$ \\
\hline Roof Displacement [in] & 0.246 & 0.516 & $110 \%$ \\
\hline Max Story Drift & 0.00076 & 0.0021 & $178 \%$ \\
\hline
\end{tabular}

\begin{tabular}{|c|c|c|c|}
\hline \multicolumn{3}{|c|}{ CM Bldg } & \\
\hline \multirow[t]{2}{*}{ Approx Bldg Weight = } & \multicolumn{2}{|c|}{3788 kips } & \\
\hline & Rigid & Semi-Rigid & Difference \\
\hline Period [sec] & 0.4 & 0.413 & $3 \%$ \\
\hline Acceleration [g] & 1.27 & 1.25 & $-2 \%$ \\
\hline Base Shear [k] & 4811 & 4735 & $-2 \%$ \\
\hline Brace Force [k] & 1788 & 1830 & $2 \%$ \\
\hline Roof Displacement [in] & 4.28 & 4.23 & $-1 \%$ \\
\hline Max Story Drift & 0.010 & 0.010 & $0 \%$ \\
\hline
\end{tabular}

There are large differences in the design forces, roof displacements, and drifts obtained from the semi-rigid and rigid computational models for the two buildings that were determined to have semi-rigid diaphragms (EWB Unit 5 and EWB Unit 3). Unlike 
Design Implications 44

the ASCE 7-05 results, both the forces and displacements increased when the diaphragm was defined as semi-rigid in the computational model. The reason that the forces increased with the SAC results and not with the ASCE 7-05 results is that the accelerations increased when using the SAC response spectrum due to the period shift caused by the difference in the stiffness between the semi-rigid and rigid diaphragm designation. As stated earlier, the ASCE 7-05 accelerations did not change between the two diaphragm designations because the period determined for both semi-rigid and rigid occurred on the response spectrum plateau.

The CM Building's parameters are nearly unaffected by the diaphragm designation. However, the consequences of idealizing a non-rigid diaphragm as rigid, in the case of EWB Unit 5 and EWB Unit 3, are an underestimation of both the forces generated in the structure and its roof displacement. The greatest difference in the forces and displacements is seen in EWB Unit 5, the building that was best modeled with a semi-rigid diaphragm. An increase of nearly $30 \%$ in the base shear would impact the design of the lateral force resisting elements of the structure, including the shear wall, the floor and roof diaphragms, the connections, and the foundation. Similar to the results from ASCE 7-05, the roof displacement and inter story drift increased dramatically in the semi-rigid diaphragm model, however, the drift is still well within the allowable maximum drift. The flexibility of the diaphragm and how it is modeled in a computational analysis affects the design forces and displacements of a building. Assuming a diaphragm to be rigid when it is not underestimates the design forces and drifts of a structure.

An Investigation of the Influence of Diaphragm Flexibility on Building Design through a Comparison of Forced Vibration Testing and Computational Analysis 
Structural Considerations 45

\subsection{STRUCTURAL CONSIDERATIONS}

In this section, structural features of each building that contributed to the results of the modal parameters and building design are investigated to give an explanation for the results obtained from both the experimental testing and the computational analysis. The results of the modal frequencies and the response seen in the mode shapes for both the experimental and computational analysis can be explained by the geometry, stiffness, mass and construction of the buildings investigated. The parameters determined by this thesis to be the most influential are the diaphragm aspect ratio, the relative stiffness of the diaphragm to the adjoining elements of the lateral force resisting system, added stiffness from non structural elements of the building, and unintentional restraint at the building edge interface with other structures.

\subsection{Relative Stiffness}

The relative stiffness of the horizontal diaphragm to the adjoining elements of the vertical lateral force resisting system was determined for each building. The combined bending and shear stiffness of the diaphragm was determined by assuming the diaphragm was a simply supported deep beam with a point load at mid span. To determine the moment of inertia of the diaphragm of the CM Building, only the concrete outside of the flutes of the metal deck profile was considered. The combined flexure and shear stiffness of the shear wall elements was determined by assuming a cantilevered wall with a point load at the wall end. The concrete was assumed to be $4 \mathrm{ksi}$ in strength. The concrete was assumed to have increased in strength over time equally between the diaphragm and walls. The stiffness of the braced frames was found by modeling the frame in computer

\footnotetext{
An Investigation of the Influence of Diaphragm Flexibility on Building Design through a Comparison of Forced Vibration Testing and Computational Analysis
} 
Structural Considerations 46

analysis software. The results for the element stiffness and the ratio between the diaphragm and vertical elements are found in Table 14 below.

Table 14. Relative Stiffness

\begin{tabular}{|c|c|c|c|c|c|c|c|}
\hline & \multicolumn{3}{|c|}{ Stiffness [k/in] } & \multirow{2}{*}{\multicolumn{2}{|c|}{$\frac{\text { Relative Stiffness }}{\text { Ratio }}$}} & \multirow{2}{*}{\multicolumn{2}{|c|}{ Aspect Ratio }} \\
\hline & \multicolumn{2}{|c|}{ Diaphragm } & \multirow{2}{*}{ LFRS } & & & & \\
\hline & Weak & Strong & & Weak & Strong & Weak & Strong \\
\hline EWB Unit 5 & 2555 & 71650 & 17405 & 0.15 & 4.12 & $2.67: 1$ & $.375: 1$ \\
\hline EWB Unit 3 & 2998 & 113148 & 8991 & 0.33 & 12.58 & $2.46: 1$ & $.407: 1$ \\
\hline CM Bldg & 2636 & 65913 & 740 & 3.56 & 89.07 & 2.63 & $.400: 1$ \\
\hline
\end{tabular}

In both EWB Unit 3 and EWB Unit 5 the ratio of the diaphragm stiffness in the weak direction to the lateral force resisting system is less than 1 . The ratio of the diaphragm stiffness in the weak direction to the lateral force resisting system of the $\mathrm{CM}$ Building is ten to twenty times higher than that of the other two buildings. The ratio in the strong direction is very large in comparison to the ratio in the weak direction for all three buildings.

There is a clear correlation between the relative stiffness of the diaphragm to the vertical elements of the lateral force resisting system and the rigid or flexible behavior of the diaphragm. As the relative stiffness increases, so does the diaphragm rigidity. In both the experiment and in the computational model, EWB Unit 5 and EWB Unit 3 exhibited flexible behavior along the diaphragms, while the CM Building diaphragm was approximately rigid. In addition to the aspect ratio, relative stiffness has an impact on the degree of flexibility in a diaphragm and should be considered when modeling the diaphragm.

A parametric study was performed to determine at what relative stiffness ratio a diaphragm appears to begin to exhibit flexibility in its response. The parameters of each 
Structural Considerations 47

building (EWB Unit 5, EWB Unit 3, and CM Building) were adjusted in their computational models. The EWB Unit 5 and EWB Unit 3 computational models were modified by increasing the relative stiffness of the diaphragm to the vertical lateral force resisting system and the CM Building computational model was modified by decreasing the relative stiffness. The deformation of the diaphragm was determined from the computational models and the relative stiffness ratio for each modified model was calculated. The results of the parametric study are plotted in Figure $\mathrm{Z}$ below.

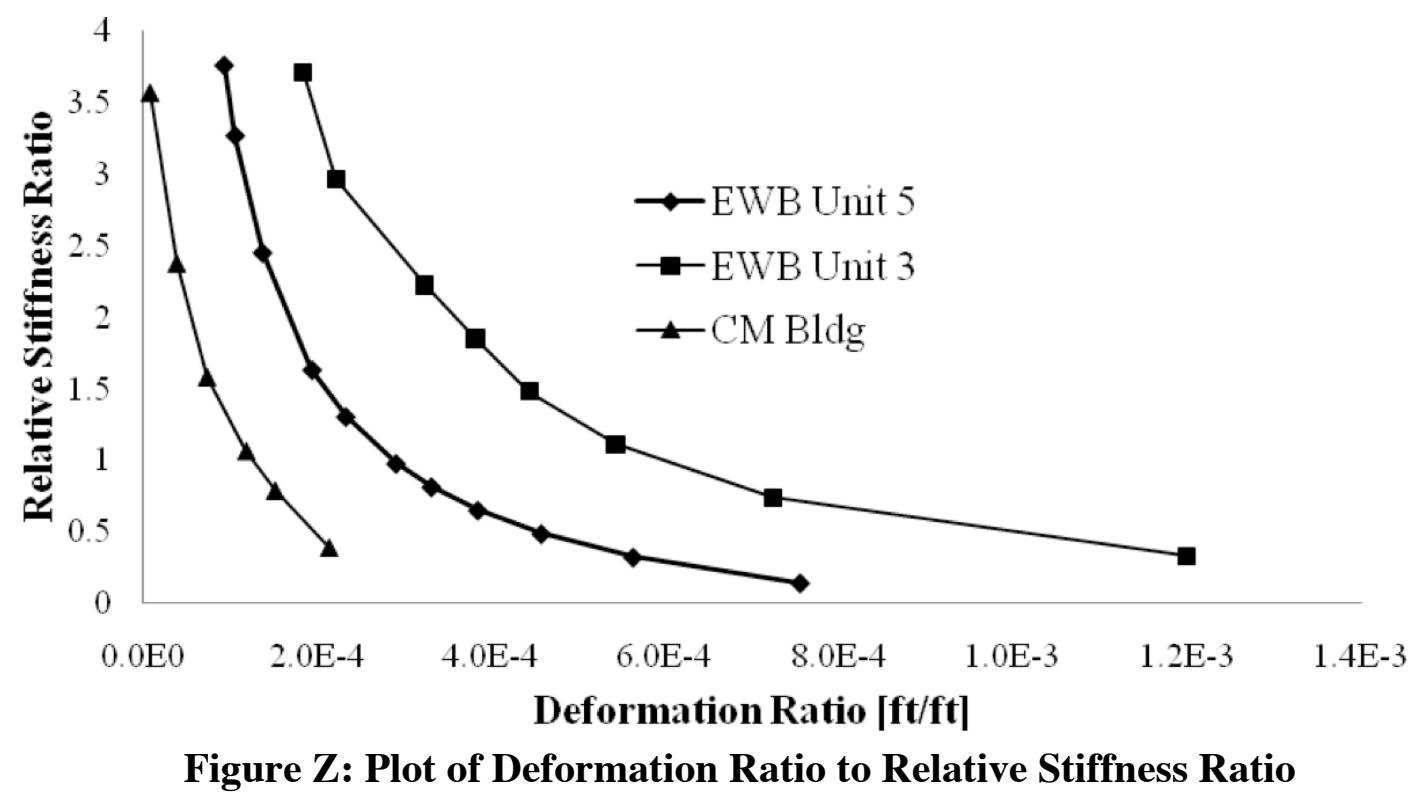

The deformation ratio was calculated by determining the non-rigid deformation in the diaphragm and dividing it by the length of the diaphragm. The non-rigid deformation was determined by mass orthonormalizing the mode shape of each building at each different relative stiffness ratio. The purpose of the parametric study was to determine at what relative stiffness ratio the diaphragm begins to have significant semi-rigid behavior. The far left of the plot represents rigidity and the far right of the plot represents flexibility. All three curves have similar shapes. Drawing lines where the curves are An Investigation of the Influence of Diaphragm Flexibility on Building Design through a Comparison of Forced Vibration Testing and Computational Analysis 
Structural Considerations 48

approximately linear as they approach zero relative stiffness and infinite relative stiffness results in these lines crossing at a relative stiffness ratio of 1.5. This suggests that diaphragms of relative stiffness less than 1.5 may be considered semi-rigid and greater than 1.5 may be considered rigid. Further research must be done to determine the relationship between relative stiffness and aspect ratio on diaphragm rigidity, because the buildings investigated in this thesis all have very similar aspect ratios. A larger set of buildings with a wider range of aspect ratios and relative stiffnesses should be investigated to determine at what point a diaphragm can and should be idealized as rigid.

\subsection{Additional Sources of Building Stiffness}

In addition to the lateral stiffness provided by the lateral force resisting system there also exists other sources of stiffness that are in the physical structure. This additional stiffness is not accounted for in the computational model and is therefore also a source of error between the experimental results and computational results. As stated in section 3.3, the directions of the first two modal periods of the CM Building were opposite that of the modal periods determined from the physical experiment. One explanation for this discrepancy could be that the nonstructural cladding on the exterior façade adds to the building stiffness more in one direction in the other. Additionally, the added stiffness from the cladding may explain why the frequencies determined experimentally were so much higher than those determined computationally. The first two modal frequencies are near each other in value $(3.6 \mathrm{~Hz}$ NS \& $3.9 \mathrm{~Hz} \mathrm{EW}$, experimentally); therefore only a small amount of stiffness added in one direction more than the other could cause these modes to swap. Steel braces with a small area $\left(4 \mathrm{in}^{2}\right.$, just 
Structural Considerations 49

over two inches in diameter) were added to the model to represent the cladding in the locations where it was present (approximately 12 braces on the north and south side of the building and only 6 braces on the west face of the building). This size of the braces was chosen arbitrarily only as an attempt to point towards an explanation of why the modes determined in the experiment were swapped from those determined in the computational model. The braces represent the cladding by providing additional stiffness only at the locations of the structure where cladding is present; i.e., on the building exterior, not at windows or doors. Because the building is longer in the east-west direction, more braces were added in that direction than the north-south, which added more stiffness in the east-west direction than in the north-south. Adding this stiffness to the structure effectively swapped the modes and the first mode then occurred in the northsouth direction, matching the experimental results.

Another source of stiffness unaccounted for in the computational model was the stairs on the west end of EWB Unit 5. It appears from the as-built drawings that the stairs were built monolithically with the building skeleton. Therefore, the stairs are adding stiffness to the building along the west line of the lateral force resisting system. The computational model used in this thesis for EWB Unit 5 did not include the stairs. However, the brick shear wall that exists along the west line was modeled the entire length of the building instead of being cut short just before the stairwell. It appears that the reduction in stiffness associated with the lack of adding the stairs into the model may have been offset by the added stiffness from the additional length of shear wall in the model. This simplification may have affected the response of the computational model 
Structural Considerations 50

for EWB Unit 5. The connection of the stairs to the building skeleton on the southeast end of the CM Building appeared to be detailed in such a way that there would be no interaction between the stairs and the building because of the isolation joint there.

Additionally, the basement of EWB Unit 3 potentially affected the overall response of the building due to its interaction with the adjacent soil. The model used in this thesis for EWB Unit 3 simplified this interaction by extending the diaphragm above the basement throughout the entire footprint of the building. This caused the diaphragm to then be pinned in space at the location where the columns and walls were pinned at their base supports. In order to most accurately model this soil interaction, the lateral stiffness of the soil would need to be determined and then springs added to the basement walls to represent this interaction. Further research needs to be performed to determine the full impact of the soil interaction on the building response of EWB Unit 3.

\subsection{Building Isolation and Seismic Joints}

Both EWB Unit 3 and the CM Building are directly adjacent to other buildings. The building edges are separated by seismic joints that act as a physical separation between the building extents. The results from the forced vibration testing suggest that the seismic joints do not allow the buildings to deflect entirely independently from each other. Accelerometers were placed on either side of the seismic joints to see how much energy was transferred from the building being forced to the building on the other side of the seismic joint. In EWB Unit 3, only on the north side of the building did there appear to be significant interaction. The responses on either side of the isolation joint, though low, were very close to each other and read approximately $9 \mu \mathrm{g}$ on the EWB Unit 3 side 
Structural Considerations 51

and $7 \mu \mathrm{g}$ on the other side. Ambient vibrations were reading in the range of 1 to $2 \mu \mathrm{g}$. This experiment suggested that the interaction between the two buildings at the point of the isolation joint caused some restraint at the building edge. Similar behavior was observed at the CM Building, but to a much lesser degree. While the response read at the west edge of the CM Building was approximately $250 \mu \mathrm{g}$ the response on the other side of the seismic joint read only between $15-20 \mu \mathrm{g}$ at the same frequency. Ambient vibrations were read at approximately $5 \mu \mathrm{g}$.

Because the level of energy applied to the system in the experiment is so low (30 pound harmonic loading transmitted by friction alone), the seismic isolation joints may still add an amount of stiffness to the system at their locations. This stiffness may be in part due to the inability of the amount of force exerted on the structure to overcome friction between touching components. In addition, the plates placed over the gap between the buildings for safe occupant mobility can cause transfer of vibrations between the adjacent buildings.

Because the actual stiffness that the interaction between building edges at the seismic isolation joints causes is not known, it was difficult to mimic this stiffness in the computational models. Modeling the seismic joint is complex and was not accurately modeled with a few linear springs defined at the edges of the building. Various attempts were made to add springs to the computational model for EWB Unit 3. However, the springs had an undesirable effect on the mode shapes of the building rather than simply shifting the building period. Further research should be done in the modeling of seismic 
Structural Considerations 52

joints between buildings in order to more accurately capture their effect on a building's response.

\subsection{Simplification of Mass Modeling}

The mass assignment was simplified in each of the models. For both EWB Unit 5 and Unit 3 an additional weight of 20 psf was assumed for the combined weight of mechanical, electrical, plumbing, partitions, and miscellaneous items otherwise unaccounted for. The building weight of the CM Building was approximated in a similar manner, however the weights for MEP, partitions, and the ceiling were delineated separately and were slightly higher than the 20 psf used for the EWB Unit 5 and Unit 3. Approximating the weight of the mechanical units, the concrete pads on which they sit, and their ductwork in a simplified manner, as was done for the purposes of this thesis, may cause the results of the computational model to be less similar to the actual physical response than if their weights were determined directly.

Several simplifications were made in the modeling of the three buildings investigated in this thesis and were discussed previously in this chapter. These simplifications may have had an effect on the response of the computational models that did not reflect the actual physical response of the building. It is understood that this discrepancy between actual response and modeled response exists and that further minimizing the number of simplifications made in the building model may have improved the correlation between the model and the building response. It may be useful to perform further research to determine the acceptable level of modeling accuracy necessary for adequate correlation between computational model and physical response. 
Conclusion 53

\subsection{CONCLUSION}

Modal parameters were determined experimentally and analytically for three buildings with concrete diaphragms. The forced vibration testing produced accelerations that were detected in the range that was expected and determined through hand calculations for the buildings tested. Computational models with a rigid diaphragm accurately predicted the response of one of the buildings while a semi-rigid diaphragm was needed to capture the flexural response of the diaphragms of the other two buildings. It is concluded that the use of forced vibration testing presented in this thesis was able to identify the flexibility in the diaphragms.

Building design forces and displacements are affected by the way a concrete diaphragm is modeled, rigid or semi-rigid. All three buildings examined in this thesis had diaphragm aspect ratios of less than three and per ASCE 7-05 thus may be idealized as rigid. However, two of the buildings exhibited flexible diaphragm action rather than the typically assumed and permitted rigid idealization. Idealizing these two buildings' concrete diaphragms as rigid resulted in an unconservative estimate of the design seismic demands. It has been shown that assessing the aspect ratio of a diaphragm alone is not sufficient to determine its rigidity in all cases. The building designer should consider the relative stiffness between the floor or roof diaphragm and the adjoining vertical lateral force resisting elements to accurately categorize the rigidity of the diaphragm. Both buildings that had flexible diaphragms had low relative stiffness ratios (relative stiffness ratio of horizontal diaphragm to adjoining vertical elements of the lateral force resisting system), 0.15 and 0.33 . The building with a rigid diaphragm had a much higher relative 
Conclusion 54

stiffness ratio, greater than three. A relative stiffness of greater than 1.5 was determined to be the point at which a diaphragm begins to exhibit rigid behavior. Further research needs to be performed to determine a more accurate ratio for the relative stiffness at which idealizing a diaphragm as rigid is acceptable for design. From the cases examined in this thesis, it was determined that a designer should consider the relative stiffness of the diaphragm to the lateral force resisting system in addition to the diaphragm aspect ratio when making a decision as to the rigidity of the diaphragm in order to estimate the building design forces and story drifts. 


\subsection{REFERENCE}

(Allemang 2003) Allemang, R. J. "The Modal Assurance Criterion - Twenty Years of Use and Abuse." Sound and Vibration, 2003.

(ASCE 7-05 2006) The Structural Engineer Institute of the American Society of Civil Engineers. "Minimum Design Loads for Buildings and Other Structures." American Society of Civil Engineers, 2006.

(Chopra 2007) Chopra, A. K. "Dynamics of Structures, Theory and Applications to Earthquake Engineering, Third Edition.” Pearson Prentice-Hall, New Jersey, 2007.

(CSI 2008) CSI. “ETABS 9.5.0 User's Guide.” Computers \& Structures Inc., Berkeley, CA, 2008.

(FEMA 355C 2000) SAC Joint Venture. "State of the Art Report on Systems Performance of Steel Moment Frames Subject to Earthquake Ground Shaking." Federal Emergency Management Agency, September 2000.

(Feng and Xue 1998) Feng, M. Q, J.-M. Kim, and H. Xue. "Identification of a Dynamic System Using Ambient Vibration Measurements.” Journal of Applied Mechanics Volume 65, Issue 4, 1010, 1998.

(Foschaar 2008) Foschaar, Jennifer C. “Ambient Vibrations of an Existing Structure.” Architectural Engineering Senior Project. California Polytechnic State University, San Luis Obispo, 2008.

(Humar 1990) Humar, J. L. “Dynamics of Structures.” Prentice-Hall, Inc., New Jersey, 1990.

(Ivanovic and Todorovska 2000) Ivanovic, S. S., M. D. Trifunac, E. I. Novikova, A. A. Gladkov and M. I. Todorovska. "Ambient Vibration Tests of a Seven-Story Reinforced Concrete Building in Van Nuys, California, Damaged by the 1994 Northridge Earthquake." Soil Dynamics and Earthquake Engineering. Volume 19, Issue 6, August 2000. 391-411.

(Ivanovic and Todorovska 2000) Ivanovic, S. S, M. D. Trifunac, M. I. Todorovska. "Ambient Vibration Tests of Structures - A Review." ISET Journal of Earthquake Technology, Paper No. 407, Vol. 37, No. 4, December 2000. 165197.

An Investigation of the Influence of Diaphragm Flexibility on Building Design through a Comparison of Forced Vibration Testing and Computational Analysis 
Reference 56

(Kondo and Hamamoto 1994). Kondo, I., and T. Hamamoto. "Local damage detection of flexible offshore platforms using ambient vibration measurement." The Proceedings of the Fourth International Offshore and Polar Engineering Conference. International Society of Offshore and Polar Engineers (ISOPE), Golden, CO, USA, 1994. 400-407.

(MathWorks 2009) MathWorks Inc. "Matlab 7 Getting Started Guide." The MathWorks Inc. Natick, MA, 2009.

(McDaniel and Archer 2009) McDaniel, C.C., Archer, G. "Developing a 'Feel' for Structural Behavior." American Society for Engineering Education (ASEE) Annual Conference, 2009.

(McDaniel and Archer 2010a) McDaniel, C.C., Archer, G. C. "Full-scale, Real-time Building Dynamics Laboratory." $9^{\text {th }}$ U.S. National and $10^{\text {th }}$ Canadian Conference on Earthquake Engineering, Earthquake Engineering Research Institute, 2010

(McDaniel and Archer 2010b) McDaniel, C.C., Archer, G. C. "Improving Student Understanding of Structural Dynamics Using Full-scale, Real-time Excitation of Buildings." American Society for Engineering Education (ASEE) Annual Conference, 2010.

(SAC 1994) SAC Steel Project. SEAOC, ATC, CUREe. Web. 19 July 2010. Richmond, CA, 1994. <http://www.sacsteel.org>.

(Skolnik and Wallace 2006) Skolnik, Derek, Eunjong Yu, Daniel W. Whang, and John W. Wallace. "Identification, Model Updating, and Response Prediction of an Instrumented 15-Story Steel-Frame Building." Eathquake Spectra, Vol. 22, No. 3, 2006. 781-802.

(Trifunac 1972) Trifunac M.D. "Comparisons Between Ambient and Forced Vibration Experiments." Earthquake Engineering and Structural Dynamics, Vol. 1, 1972. 133-150.

(Yu 2005) Yu, E. "Forced Vibration Testing and Analytical Modeling of a Four-Story Reinforced Concrete Frame Building." PhD Thesis, Department of Civil Engineering, University of California, Los Angeles. 2005.

(Yu and Wallace 2008) Yu, E., D. Skolnik, D. Whang, J. Wallace. "Forced Vibration Testing of a Four-Story Reinforced Concrete Building Utilizing the nees@UCLA Mobile Field Laboratory.” Earthquake Spectra, Vol. 24, No. 4, 2008.

An Investigation of the Influence of Diaphragm Flexibility on Building Design through a Comparison of Forced Vibration Testing and Computational Analysis 